Review

\title{
The Influence of Surface Alumina and Silica on the Photocatalytic Degradation of Organic Pollutants
}

\section{Terry A. Egerton}

School of Chemical Engineering and Advanced Materials, Merz Court, University of Newcastle upon Tyne, Newcastle upon Tyne NE1 7RU, UK; E-Mail: Terry.Egerton@ncl.ac.uk; Tel.: +44-191-645732

Received: 23 November 2012; in revised form: 21 January 2013 / Accepted: 7 February 2013 /

Published: 21 March 2013

\begin{abstract}
Practical photocatalysis for degradation of organic pollutants must take into account the influence of other chemicals. Significant Al deposition on titania can occur at naturally occurring concentrations of dissolved Al. This paper reviews the author's work on the influence of deliberately deposited hydrous oxides of aluminium on the behavior of $\mathrm{a} \sim 130 \mathrm{~m}^{2} \mathrm{~g}^{-1}$ rutile $\mathrm{TiO}_{2}$, and then compares the behavior of deposited alumina with that of deposited silica. On rutile some adsorbed nitrogen is infrared-active. Alumina and silica deposited on the rutile reduce, and ultimately eliminate, this infrared-active species. They also reduce photocatalytic oxidation of both propan-2-ol and dichloroacetate ion and the photocatalytic reduction of diphenyl picryl hydrazine. The surface oxides suppress charge transfer and may also reduce reactant adsorption. Quantitative measurement of $\mathrm{TiO}_{2}$ photogreying shows that the adsorbed inorganics also reduce photogreying, attributed to the capture of photogenerated conduction band electrons by $\mathrm{Ti}^{4+}$ to form $\mathrm{Ti}^{3+}$. The influence of adsorbed phosphate on photocatalysis is briefly considered, since phosphate reduces photocatalytic disinfection. In the context of classical colloid studies, it is concluded that inorganic species in water can significantly reduce photoactivity from the levels that measured in pure water.
\end{abstract}

Keywords: photocatalysis; rutile; silica; alumina; coating; oxidation; reduction; photogreying 


\section{Introduction and Scope}

This paper briefly reviews work carried out by the author and colleagues on the effect of surface oxides on the photocatalytic activity of titanium dioxide. Although many studies have highlighted the potential of $\mathrm{TiO}_{2}$ photocatalysis for the degradation of organic pollutants, especially dye residues in aqueous effluent [1-3], any practical application must consider the influence of other chemicals, of either natural or anthropogenic origin, in the water to be treated. Aluminium may be introduced as a flocculant in water treatment systems or as a mordant in dyehouses and although the concentrations of naturally occurring aluminium in the world's major rivers are highly variable they may be as high as $100 \mu \mathrm{M}$ [4-7]. Classical colloid studies on model systems, summarized in the discussion section below, have shown significant adsorption of aluminium species on titania surfaces at these concentrations [8-11] and this paper considers the influence on photocatalytic activity of hydrous oxides of aluminium deliberately deposited on the $\mathrm{TiO}_{2}$ surface. Silica, also, may be present in freshwater [12], often as a silica-alumina species [13]. Therefore, the effects of adsorbed silica are compared with those of adsorbed alumina.

Although many practical studies of pollutant degradation are carried out with $\mathrm{P} 25 \mathrm{TiO}_{2}$, its composite nature ( $\sim 20 / 80$ rutile/anatase) would, in general, complicate the interpretation of the effects of alumina and of silica deposition because of the existence of both rutile and anatase surfaces and the possibility of surface alumina or silica blocking charge-carrier transfer between the two crystal forms. The use of either a pure rutile or a pure anatase to demonstrate the effects of surface oxide deposition avoids this complication. Therefore, a high area rutile, with a photocatalytic activity comparable with P25 has been chosen for this study.

\section{Materials and Their Characterization}

\subsection{Preparation of Alumina and Silica Coatings on High Area Rutile}

The rutile used for the majority of the studies described in this paper was prepared by the aqueous hydrolysis of $\mathrm{TiCl}_{4}$ and supplied by the Solaveil business of Uniqema (now Croda Chemicals). The characterization of similar particles has been described more fully elsewhere $[14,15]$. Two different $\mathrm{TiO}_{2}$ batches (\#1;140 $\mathrm{m}^{2} \mathrm{~g}^{-1}$ and \#2;123 $\mathrm{m}^{2} \mathrm{~g}^{-1}$ ), were used for the experiments reported in this paper. XRD confirmed that both products were rutile and broadening of the 110 rutile diffraction line suggested that the primary units had a dimension of 7-10 $\mathrm{nm}$ in a direction perpendicular to the 110 crystal plane. Electron microscopy showed the existence of lenticular primary units approximately $70 \mathrm{~nm}$ in length and $\sim 10 \mathrm{~nm}$ across. A typical transmission electron micrograph, Figure 1A, shows that the primary units often form clusters in which the c-axis of the primary crystals are oriented parallel to one another-rather like a group of pencils which are held by a weak rubber band which allows individual units to slip lengthwise w.r.t. to one another. 
Figure 1. (A) Transmission electron micrograph of Rutile \#1. The red bar represents $100 \mathrm{~nm}$; (B) Comparison of the photocatalytic activity for propan-2-ol oxidation of Rutile (\#1) and P25 as a function of catalyst concentration.

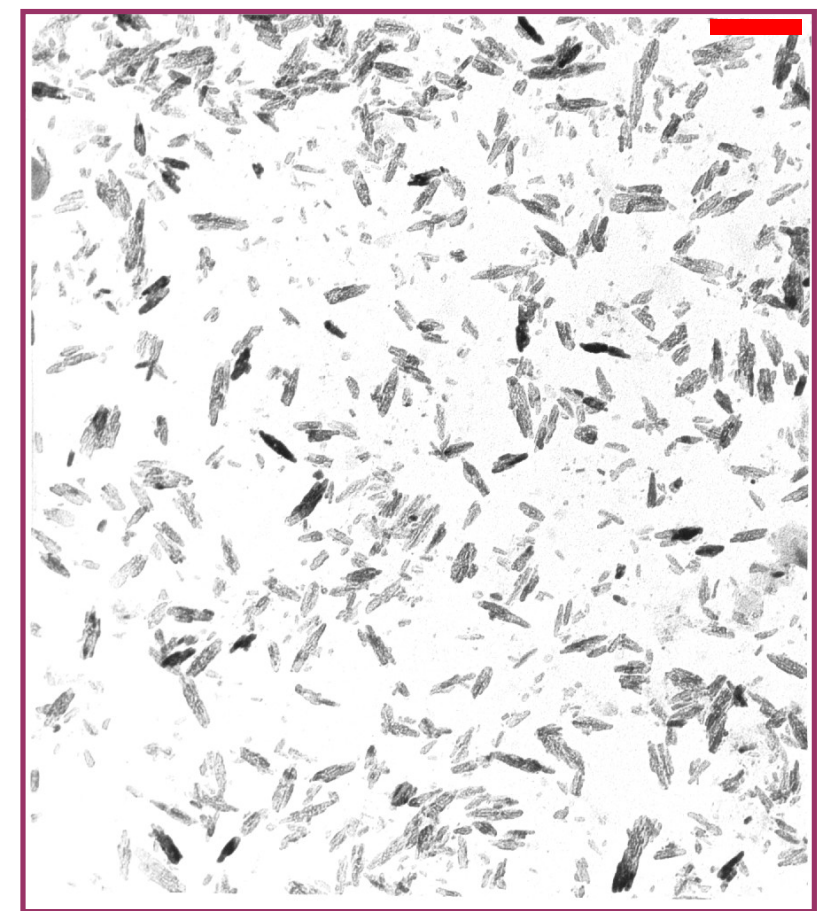

(A)

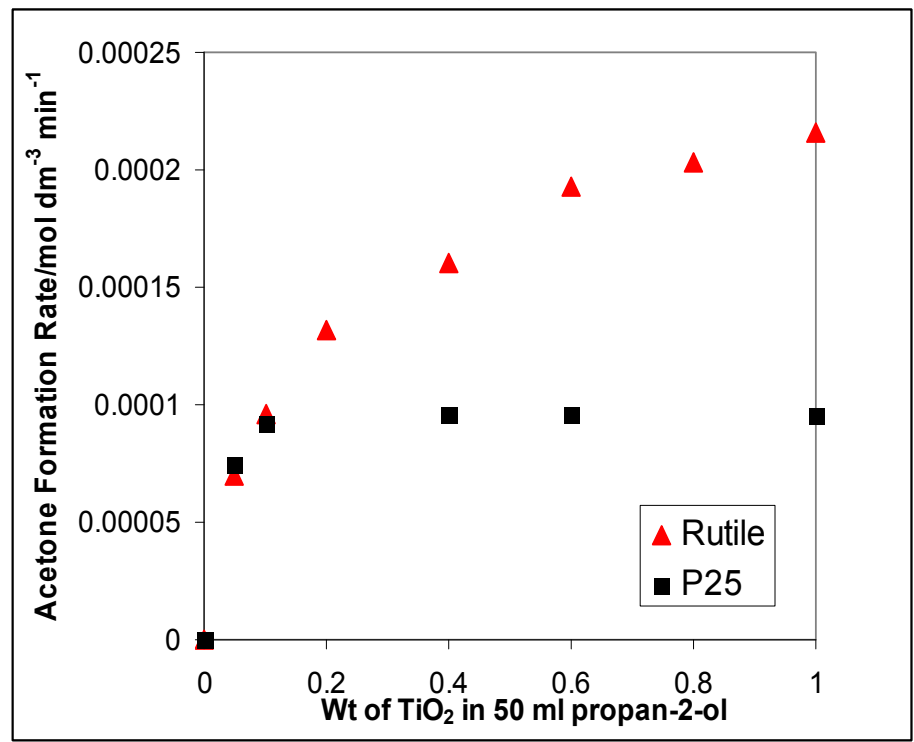

(B)

The photocatalytic activity for oxidation of propan-2-ol of this rutile is demonstrated by the comparison, in Figure 1B, with that of the well known catalyst P25.

Results are reported here for two series of "alumina" coatings $\left(1 \mathrm{~A}\right.$ on $\mathrm{TiO}_{2} \# 1$, and $2 \mathrm{~A}$ on $\left.\mathrm{TiO}_{2} \# 2\right)$ and for two different series of silica "coatings" (1S on $\mathrm{TiO}_{2} \# 1,2 \mathrm{~S}$ on $\mathrm{TiO}_{2} \# 2$.). In natural waters, the mechanisms of alumina or silica deposition on $\mathrm{TiO}_{2}$, are greatly perturbed from those associated with deliberate coating deposition [16-19] by both the composition and history of the water. For example, in the presence of silicic acid, the size and charge distribution profiles of aluminium species are 
significantly changed from those normally associated with aluminium hydroxide chemistry, perhaps because aluminium hydroxide polymerization is inhibited [20]. They are also time dependent. [20]. Further, the relative strengths of binding of silicate, sulphate and phosphate to hydroxyl aluminium species is $\mathrm{pH}$ dependent; at $\mathrm{pH}>5$ silicate binds more strongly than sulphate and at $\mathrm{pH}>6.6$ silicate binds more strongly than phosphate [21]. Further perturbation occurs because aluminium in natural water may be complexed by naturally occurring organic matter, e.g., humic acids [22] and the efficiency of this complexation may be changed by the presence of other ions [23] or oxidative pre-treatment such as ozonation [24] Therefore, instead of attempting to mimic the mechanisms that take place in natural waters, the oxides have been deposited on the $\mathrm{TiO}_{2}$ by well defined routes. "Alumina" coatings of series 1A were prepared by precipitation of a hydrous alumina onto a polyphosphate dispersed suspension $\left(30 \mathrm{~g} \mathrm{dm}^{-3}\right)$ of rutile in water [15]. Aluminium sulfate was added at a controlled $\mathrm{pH}$ of 3.0 followed by caustic sodium aluminate at a controlled $\mathrm{pH}$ of 10 . The resulting dispersion was then neutralized, filtered, washed and dried in air at $110{ }^{\circ} \mathrm{C}$. Alumina coatings on series 2A samples were prepared by dropwise addition of caustic sodium aluminate to an aqueous slurry of $\mathrm{TiO}_{2} \# 2$ at $50{ }^{\circ} \mathrm{C}$ [14]. The slurry was then neutralized with $\mathrm{HCl}$, filtered and washed. Thus the coatings on series $2 \mathrm{~A}$ were by a much simpler route than the coatings of series $1 \mathrm{~A}$. Both sets of "silica" coatings were prepared by the same route, Iler's "dense silica" method [17]. The silica levels of the $1 \mathrm{~S}$ series were determined as $0.5,2.3,8.9$ and $20 \%$ by XRF. The target levels of the $2 \mathrm{~S}$ series were $0.1,0.25,0.5(0.7), 1,3$ (3.2), 5 and 10 (9.1)\% silica; the XRF analyses are given in parentheses. Zeta potential results provided by Dr. I. R. Tooley (Croda) showed that the isoelectric point, i.e.p., fell from a $\mathrm{pH}$ of $\sim 5.7$ for the uncoated rutile to a $\mathrm{pH}$ of $\sim 2.8$ for the $5 \%$ silica sample.

To demonstrate that the "coatings" exist on the $\mathrm{TiO}_{2}$ surface, and that deposition does not simply results in a mixture of bulk silica and bulk titania, further characterization was carried out by solid state n.m.r. and by i.r. spectroscopy of adsorbed nitrogen.

\subsection{NMR Characterization of Silica and Alumina Coated $123 \mathrm{~m}^{2} \mathrm{~g}^{-1}$ Rutile}

The solid state ${ }^{29} \mathrm{Si}$ magic angle spinning (MAS) n.m.r. spectra were measured on $0.7,3.2,5$ and 9.1\% silica coated rutiles (series $2 \mathrm{~S}$ ). Figure $2 \mathrm{~A}$ compares the spectrum of the $5 \%$ silica coating with that of a physical mixture of $5 \%$ aerosil $\mathrm{SiO}_{2}$ with $95 \% \mathrm{TiO}_{2}$. Had the "coating" procedure created a separate silica precipitate the two spectra would look the same. Instead they are very different. Consideration of the chemical shifts [25] suggests that the physical mix contains a large amount of silicon

$\mathrm{Q}^{4}\left[\mathrm{Si}(\mathrm{OSi})_{4}\right]$ and $\mathrm{Q}^{3}\left[\mathrm{OSi}(\mathrm{OSi})_{3}\right]$ environments whereas the chemically bonded silica- $\mathrm{TiO}_{2}$ contains predominantly $\mathrm{Q}^{2} \quad\left[\mathrm{O}_{2} \mathrm{Si}(\mathrm{OSi})_{2}\right]$ and $\mathrm{Q}^{1} \quad\left[\mathrm{O}_{3} \mathrm{SiOSi}\right]$ environments. These results indicate that cross-linking of the $\mathrm{Si}(\mathrm{OH})_{4}$ is much less in the coating than in the aerosil. The possibility that the reduced cross-linking was because of the low temperature at which the coating silica had been deposited was excluded by the negligible difference between spectra of a $3 \%$ coated sample before and after $450{ }^{\circ} \mathrm{C}$ heat-treatment, Figure $2 \mathrm{~B}$. Overall, the solid state n.m.r. results give confidence that the silica does not exist as a separate silica precipitate [26]. 
Figure 2. (A) Comparison of ${ }^{29} \mathrm{Si}$ MAS n.m.r. spectra of a $5 \mathrm{wt} \%$ silica- $95 \% \mathrm{TiO}_{2}$ physical mix (thick line) and a $5 \mathrm{wt} \%$ silica- $\mathrm{TiO}_{2}$ surface coated sample (thin line) prepared by Iler's “dense silica" method (series $2 \mathrm{~S}$ ); (B) N.m.r. of $3.2 \mathrm{wt} \%$ silica-TiO ${ }_{2}$ before (red) and after (black) heat treatment at $450^{\circ} \mathrm{C}$ (series $2 \mathrm{~S}$ ).

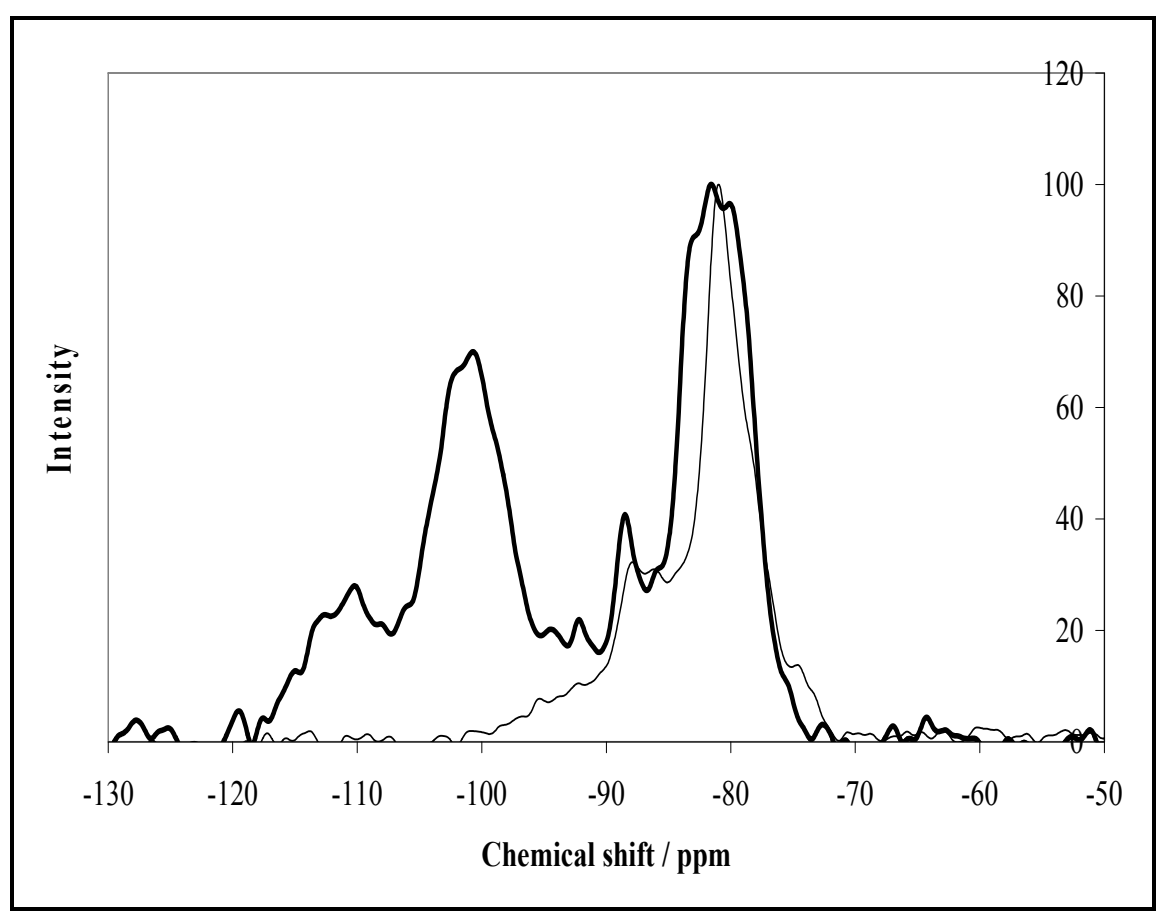

(A)

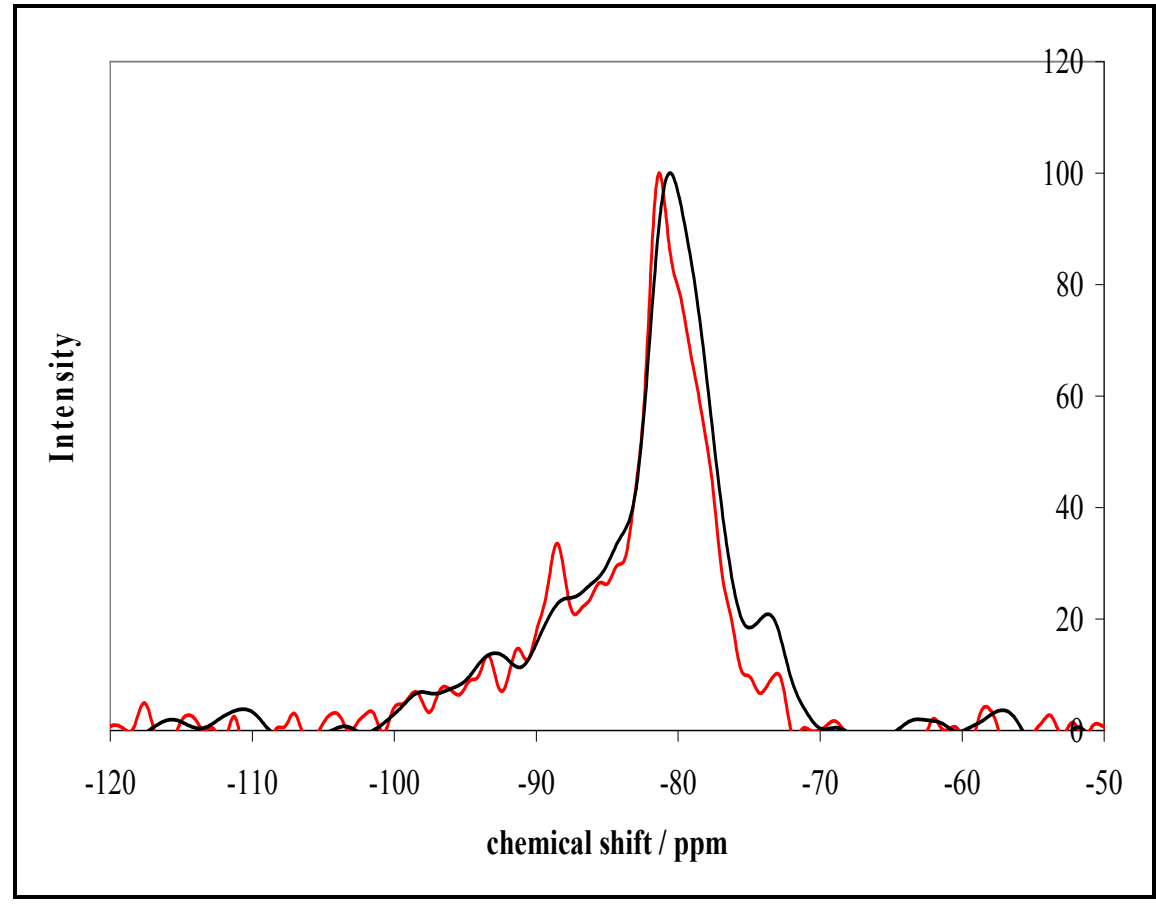

(B)

Analogous experiments on alumina coated $\mathrm{TiO}_{2}$ are more difficult to interpret, because of the quadrupole moment of ${ }^{27} \mathrm{Al}$ [25]. Although the ${ }^{27} \mathrm{Al}$ spectra of $1 \%$ alumina and $25 \%$ alumina coatings are very similar, after allowing for the noise due to the low levels of $\mathrm{Al}$ in the $1 \mathrm{wt} \%$ alumina sample, it is clear that the peak of the $25 \mathrm{wt} \%$ alumina sample is more symmetrical than that of the $1 \mathrm{wt} \%$ 
alumina sample. This asymmetry suggests that the aluminium environment associated with the $25 \mathrm{wt} \%$ sample is more ordered and this is confirmed by the presence of spinning sidebands (arising from satellite transitions due to the quadrupolar nature of aluminium). It is concluded that the aluminium environment is similar for all loadings and that this is an octahedral environment (with perhaps a minor peak at $\sim 60$ p.p.m. indicating that $2 \%$ of the spectral intensity of the $25 \%$ sample is associated with tetrahedral aluminium). It is reasonable to suggest that the disorder at low levels of alumina is due to perturbation of Al's on the surface of the rutile and that this perturbation decreases as the alumina layer becomes thicker with increasing amounts of alumina.

Figure 3. ${ }^{27} \mathrm{Al}$ MAS n.m.r. spectra of $\mathrm{TiO}_{2}$ /alumina prepared with $1 \mathrm{wt} \%$ alumina (red) and $25 \mathrm{wt} \%$ alumina (black) on rutile (series 2A). Sensitivities have been adjusted to facilitate comparison of the two signals.

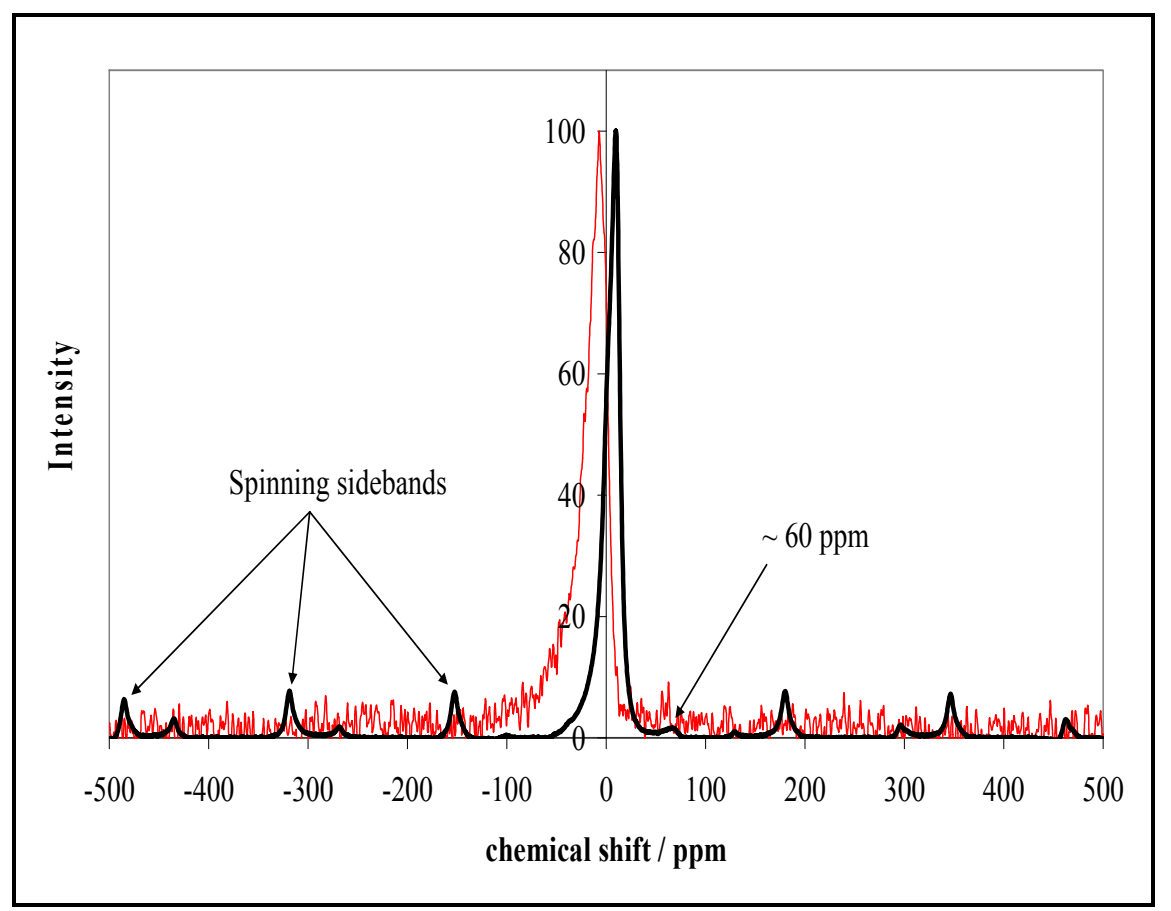

\subsection{Characterization by IR Spectroscopy of Adsorbed Nitrogen}

Infrared transmission spectra (256 scans, $2 \mathrm{~cm}^{-1}$ resolution) of adsorbed nitrogen were measured on thin pressed discs of \#1 rutile, and on both alumina (1A) and silica (1B) coated rutile, placed in a specially constructed cell, in which they could be heated in vacuum prior to prior to exposure to nitrogen at $\sim-120 \mathrm{~K}$. Full details are given elsewhere [15]. Gas phase nitrogen is infrared inactive, because nitrogen has no permanent dipole. Physically adsorbed nitrogen normally remains i.r. inactive, and as shown later in this section, no i.r. absorption was detectable when nitrogen was physically adsorbed on either silica or alumina. By contrast, the transmission i.r spectra of pressed discs of $\mathrm{TiO}_{2}$ cooled to $\sim 120 \mathrm{~K}$, Figure 4, demonstrated that on rutile some adsorbed nitrogen is infrared active [15]. In nitrogen the spectrum showed a weak absorption near $\sim 2335 \mathrm{~cm}^{-1}$ which, as shown in the inset to Figure 4, became more intense with increasing nitrogen pressure and was absent from the spectrum of the same disc measured in vacuum. This absorption was assigned to adsorbed dinitrogen because it was very close to the $2331 \mathrm{~cm}^{-1}$ Raman band associated with the stretching-vibration of nitrogen gas; 
it is considered to be due to $\mathrm{N}_{2}$ adsorbed on specific sites on titania at which the presence of a strong electrostatic field makes the $\mathrm{N}-\mathrm{N}$ stretching vibration i.r.-active. Absorption at $2258 \mathrm{~cm}^{-1}$ in the spectrum of adsorbed ${ }^{15} \mathrm{~N}_{2}$ confirmed the assignment since its frequency agreed well with the calculated value of $2256 \mathrm{~cm}^{-1}$ for isotopically shifted dinitrogen. Similar absorption was found for $\mathrm{N}_{2}$ adsorbed on P25 titania.

Figure 4. The single beam spectrum of $\mathrm{N}_{2}$ on high area rutile, sample $\mathrm{A}$, before (lower spectrum) and after (upper spectrum) adsorption of $\mathrm{N}_{2}$. (Bands in the $\mathrm{CH}$ stretching region are artefacts due to grease vapour condensed on the windows and are present in the blank spectrum). The inset shows an enlargement of the $2320-2360 \mathrm{~cm}^{-1}$ region of the spectrum at: (a) 0 ; (b) 1; (c) 1.5; (d) 2.7; (e) 4.9; (f) 6.8; and (g) $9.7 \mathrm{kPa}$ of $\mathrm{N}_{2}$. (Taken from Egerton T.A. et al. [15] Reproduced by permission of The Royal Society of Chemistry (RSC).

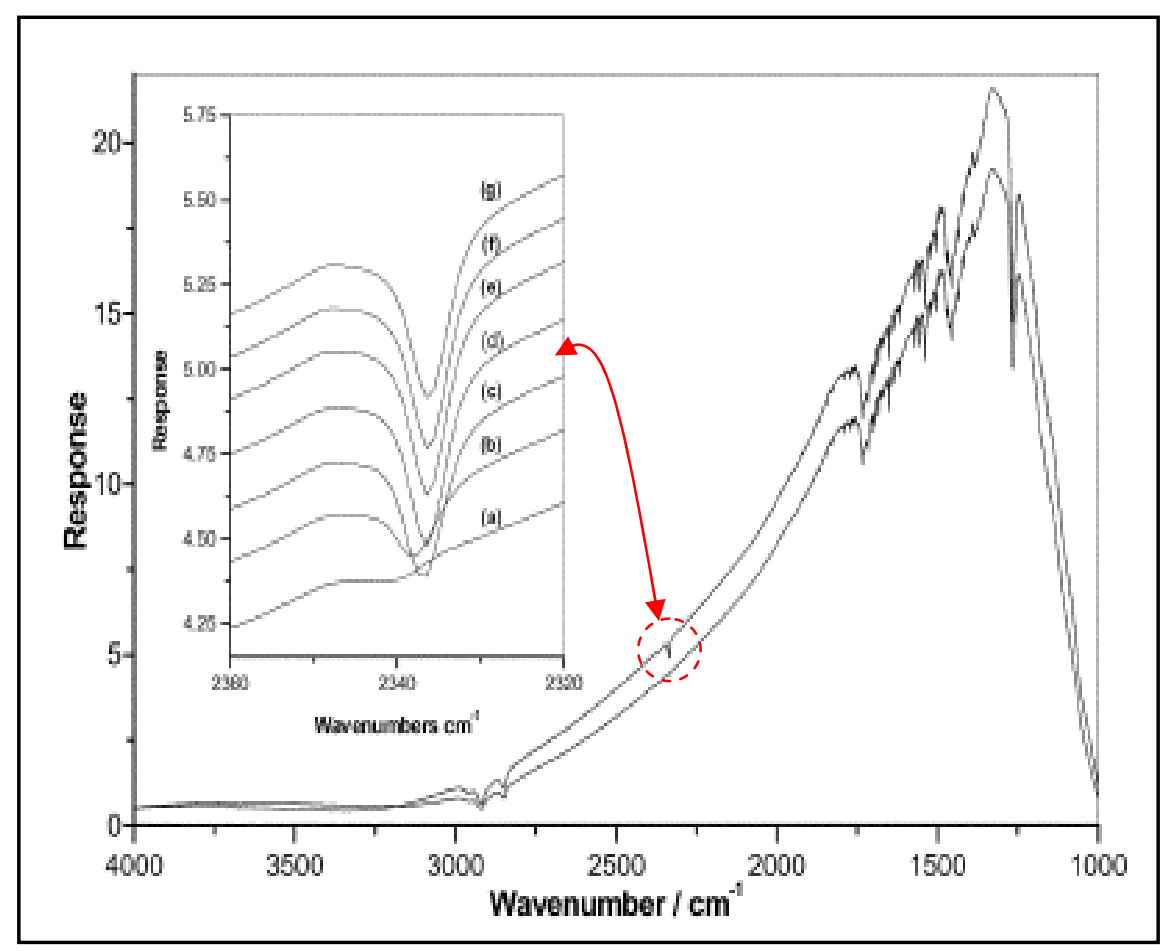

The experiments were then repeated using samples prepared by depositing (a) hydrous alumina (series 1A) and (b) silica (1S) to form a coating on the same preparation of high area rutile that had been used for the initial spectroscopic studies of adsorbed nitrogen. In both cases i.r. absorption of surface nitrogen was measured as a function of pressure and, as shown in Figure 5, was weaker than on the uncoated rutile. This implies that both alumina and silica block the surface sites on rutile at which nitrogen adsorbs in i.r.-active form. Thus, i.r. the results support the conclusions from n.m.r. that both alumina and silica are deposited on the $\mathrm{TiO}_{2}$.

By repeating the measurements using rutile coated with increasing quantities of alumina the dependence of the strength of the nitrogen signal on the amount of surface alumina was established. This variation is plotted relative to the i.r. absorption of the uncoated rutile in Figure 6A. The corresponding results for silica coatings are plotted in Figure 6B. 
Figure 5. The dependence of the $\mathrm{N}_{2}$ absorption at $2335 \mathrm{~cm}^{-1}$ on the presence of $15 \%$ alumina or $8.9 \%$ silica deposited on the surface of the high area rutile \#1. No $2335 \mathrm{~cm}^{-1}$ absorption was measured on Aerosil or Alon C. All measurements were made at $\sim-150{ }^{\circ} \mathrm{C}$ $(123 \mathrm{~K})$.

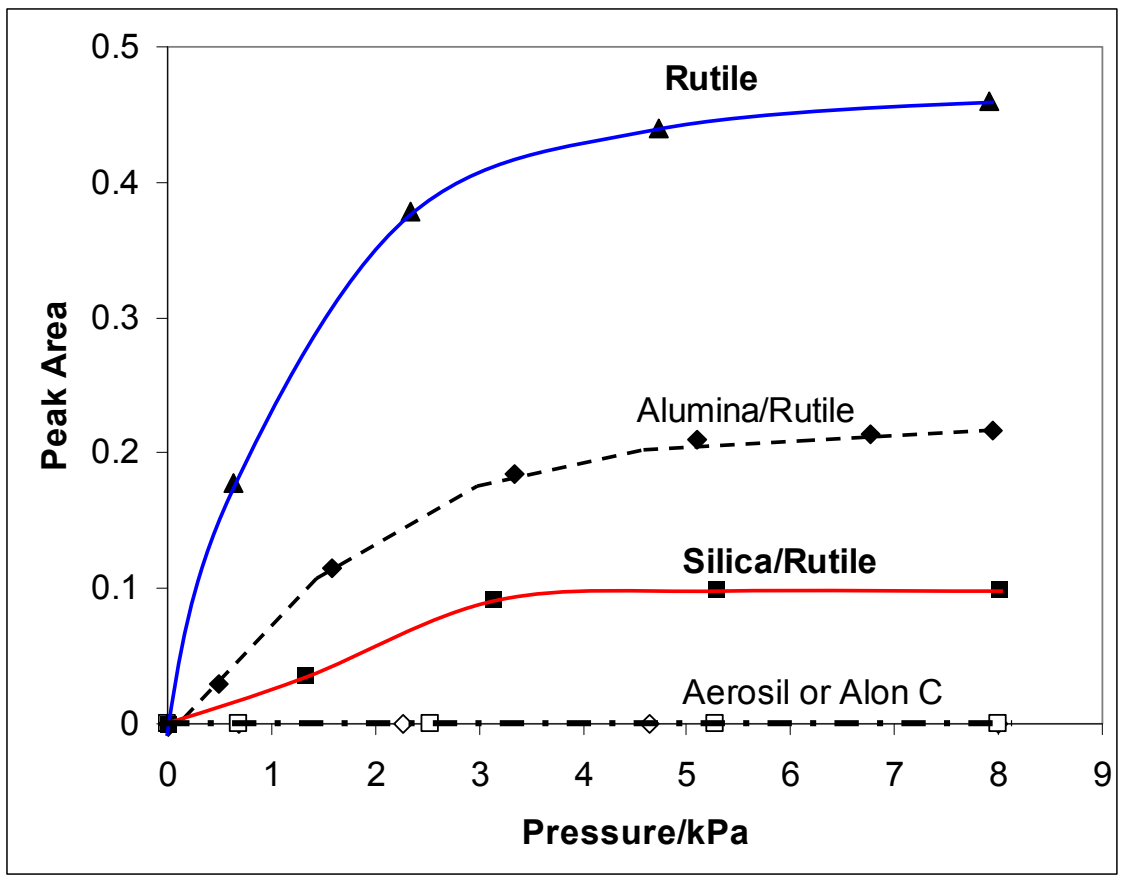

\section{Photocatalytic Oxidation}

Two reactions have been used to probe photocatalytic oxidation. The first is the oxidation of a neutral molecule, propan-2-ol, in the form of the pure liquid [15]. As propan-2-ol is uncharged, its interaction with the catalyst surface is expected to be relatively insensitive to changes in the surface charge on the $\mathrm{TiO}_{2}$ particle caused by coating. Further, previous work comparing vapour adsorption of ethanol on titania and on the same titania coated with either silica or alumina revealed that on all three samples the adsorption was strong and specific with an isotherm form close to that of type I. This was interpreted as the surface of the coated samples being highly hydrated and having the same potential as the uncoated $\mathrm{TiO}_{2}$ to interact with polar molecules [27]. Consequently, any changes in propanol oxidation were expected to be primarily a consequence of suppressed charge-carrier transfer.

By contrast, oxidation of an aqueous solution of dichloroacetate anion at $\mathrm{pH} 3$ is expected to be affected by changes in surface charge. At pH 3 the surface of titania is positively charged whilst the surface of silica is much less positive, or negative. It might therefore be expected that changes in catalytic activity due to suppressed charge-transfer on silica coated surfaces would be supplemented by the consequences of reduced adsorption of the DCA anion. 


\subsection{Photocatalytic Oxidation of Propan-2-ol}

The photocatalytic activities of the alumina-coated rutiles (series 1A) for the oxidation of liquid propan-2-ol to acetone were measured chromatographically, as detailed elsewhere [15] and the activities compared with the activity of the untreated rutile \#1. The results, Figure $6 \mathrm{~A}$, show that the effect of the surface alumina on the photocatalytic activity was broadly similar to its effect on the intensity of the nitrogen absorption. Both effects were eliminated by ca. $30 \%$ of alumina. A corresponding plot for series 1S silica coated rutiles is shown in Figure 6B. The effects of surface silica on the i.r.-active nitrogen and on the photocatalytic activity were again very similar and even more marked than those of alumina. It appears that as alumina (or silica) covers the surface it inhibits the transfer of positive-holes to $\mathrm{OH}^{-}$and thus prevents the formation of the hydroxyl radicals responsible for propanol oxidation.

The strategy was repeated for the silica-on-rutile series $2 \mathrm{~S}$ prepared from rutile \#2 [26]. The results (Figure 7A) again show that, above 1\% silica, deposition of silica reduces the activity for propan-2-ol photocatalytic oxidation. Extrapolation of the linear plot of Figure 7A suggests that the activity for acetone production is almost eliminated by $\sim 12 \%$ silica. Lower levels of silica, up to $0.5 \%$, cause a small increase in activity (Figure 7B) but above this level the activity $v s$. coating level plot fall more linearly than in the $\mathrm{N}_{2}$ and propan-2-ol oxidation experiments of Figure $6 \mathrm{~B}$. The reasons for this difference have not been identified; the variation may imply a different distribution of active sites on rutiles \#1 and \#2.

Figure 6. (A) The effect of surface alumina and (B) the effect of surface silica on the intensity of the IR of adsorbed nitrogen (at $8 \mathrm{kPa} \mathrm{N}$ ) and on the activity for photocatalytic oxidation of propan-2-ol. Both sets of results are normalized relative to the result for the untreated starting rutile-\#1.

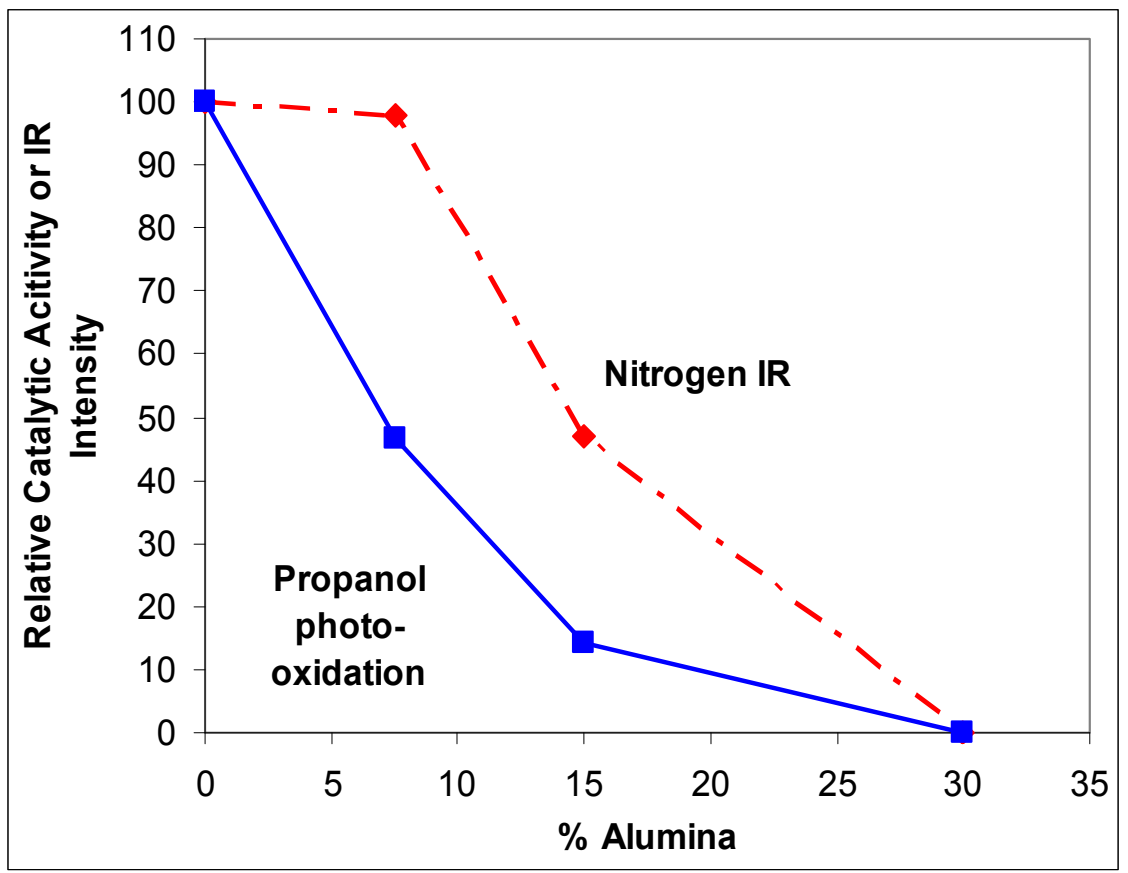

(A) 
Figure 6. Cont.

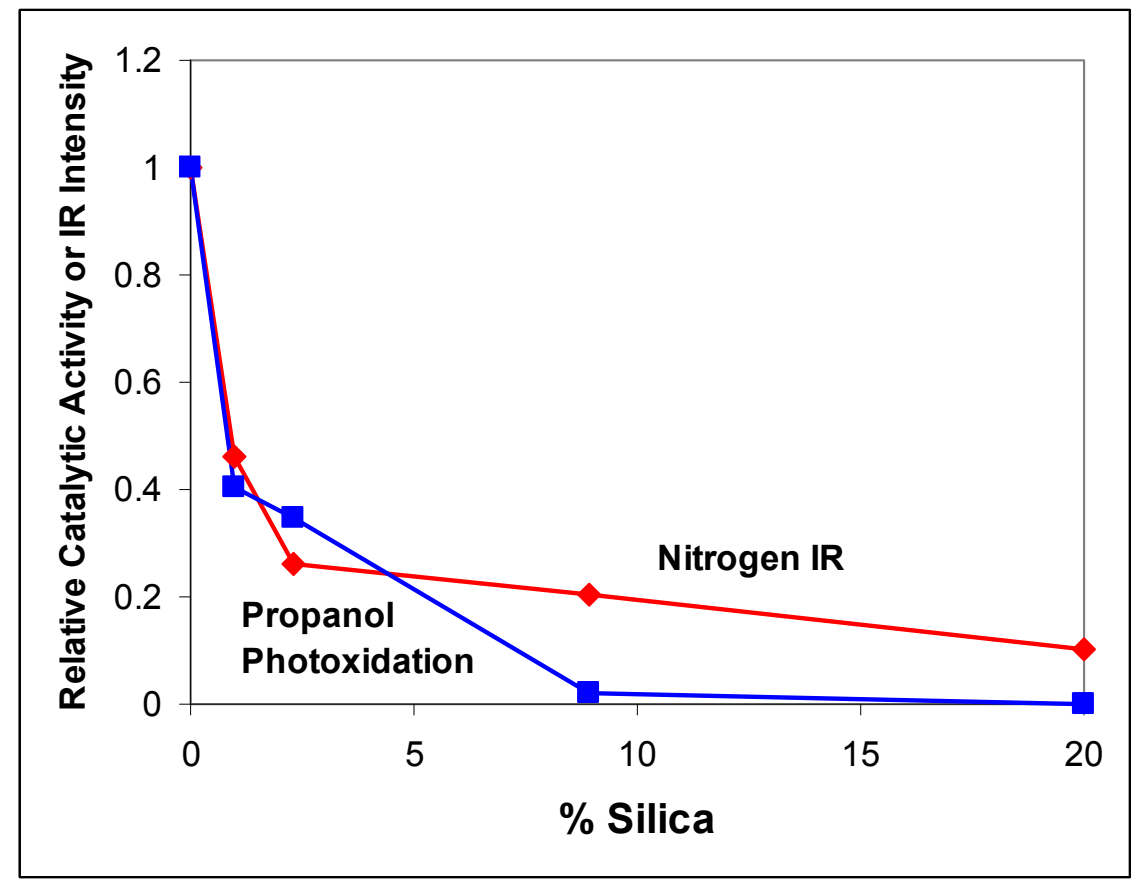

(B)

Figure 7. (A) Decrease in relative rates of propan-2-ol oxidation at high levels of silica deposited on rutile \#2. (The activity of rutile 2 is taken as 1.0.); (B) Changes in the relative rates of propan-2-ol oxidation for rutile \#2 coated with increasing amounts of alumina (-), and silica (---). In both cases, the uncoated $\mathrm{TiO}_{2}$ has a rate of 1 and all other rates are relative to this.

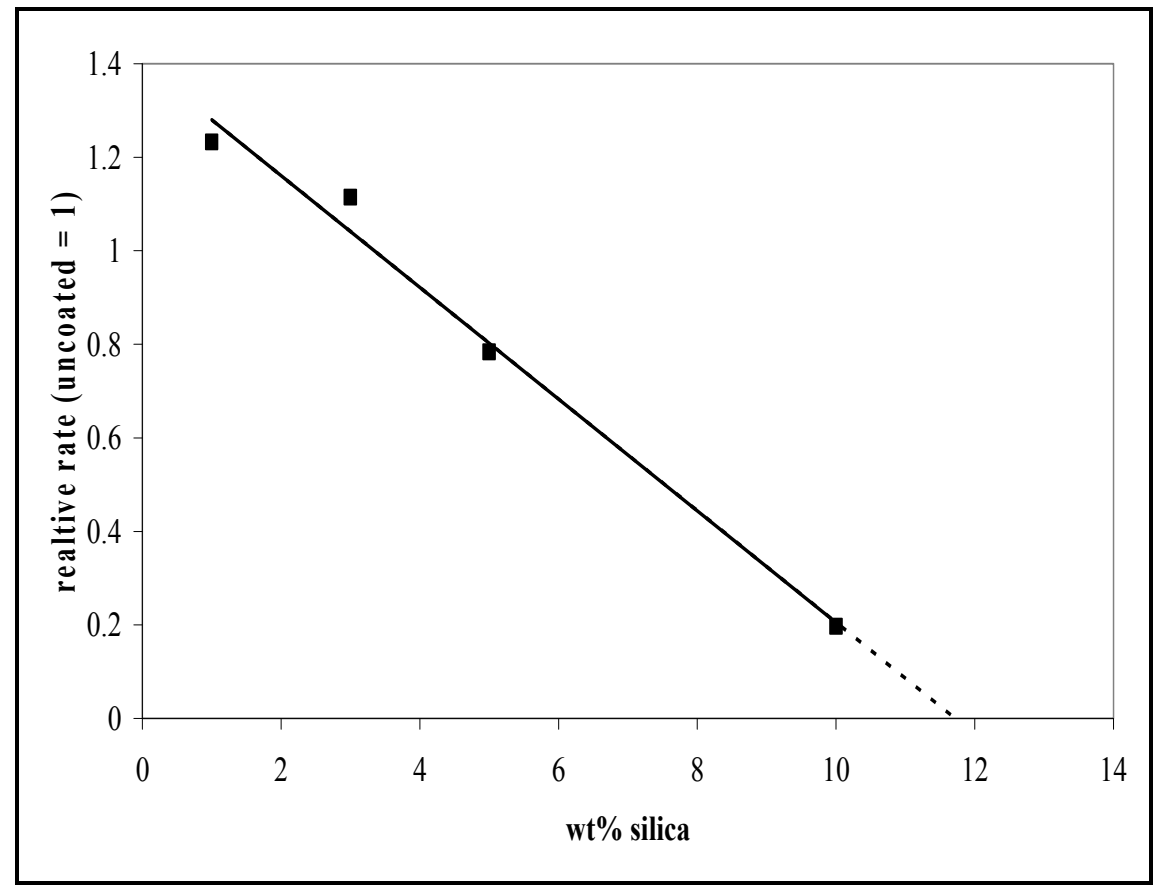


Figure 7. Cont.

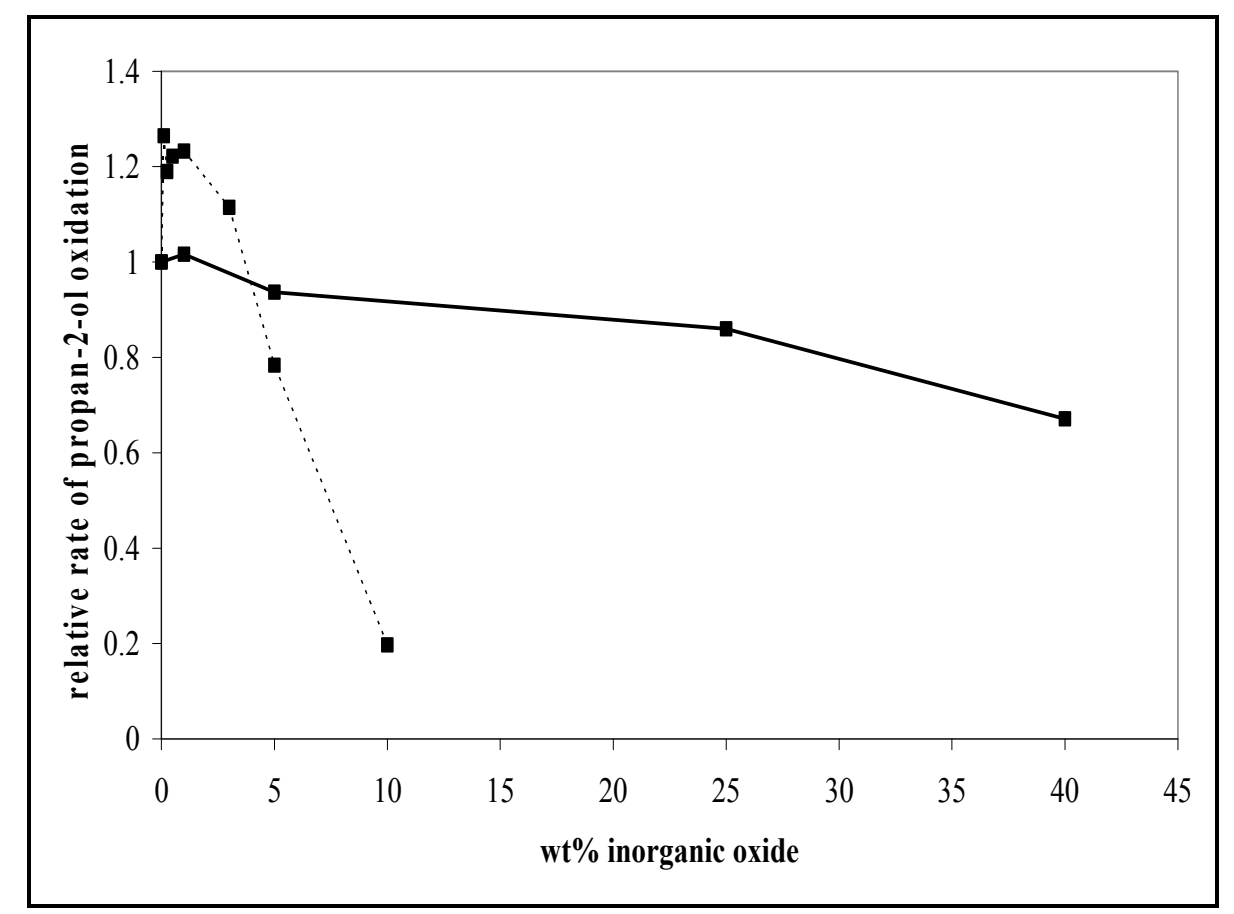

(B)

The effect of alumina (series 2A) and silica (series 2S) deposition on rutile (\#2) on the oxidation of propan-2-ol are compared in Figure 7B. As for the experiments with 1A and1S, alumina reduces activity less effectively than does silica, but deposition of alumina on rutile \#2 reduced photocatalysis by a smaller amount than deposition on rutile \#1 (Figure 6A). This is probably due to differences in the quality of the coating resulting from the simpler alumina deposition process.

\subsection{The Photocatalytic Oxidation of DCA}

To test the generality of the results, the photocatalytic degradation of dichloroacetic acid (DCA) was then measured at $\mathrm{pH} 3$ on the silica coated rutiles (2S) [28]. Since the $\mathrm{pK}_{\mathrm{A}}$ of DCA is 1.3, the dichloroacetate ion is the predominant species at $\mathrm{pH} 3$. DCA degradation was selected as a test reaction because, unlike propan-2-ol oxidation but like other saturated carboxylic acids, DCA degradation is believed to proceed by direct-hole mechanism under these conditions [29]. The direct correlation between the initial rate of DCA photodegradation and the specific surface area of anatase nanoparticles supports this interpretation [30]. Unlike the results for propan-2-ol, the activity was not completely eliminated at higher silica levels. However, once again, after an initial small increase at very low silica levels, the photocatalytic activity decreased, to $25 \%$ of that of uncoated rutile on deposition of only 3-5\% silica. I.e. the DCA oxidation rate reduced more rapidly than the propan-2-ol oxidation rate. Direct-hole degradation of carboxylic acids, such as DCA, has been shown to be more sensitive to surface area variation than are reactions, such as propan-2-ol oxidation that are mediated by the diffusible $\mathrm{OH}$ radicals [31] and this sensitivity has been interpreted as a consequence of the need for reactant adsorption when the mechanism is direct hole-transfer. As discussed further in Section 6.2, the large change in the DCA oxidation activity associated with low silica loadings is a 
probable consequence of the silica suppressing DCA adsorption in addition to reducing whole transfer to it.

Figure 8. Decrease in relative rates of dichloracetate oxidation at high levels of silica deposited on rutile $\# 2$. (The activity of rutile $\# 2$ is taken as 1 ).

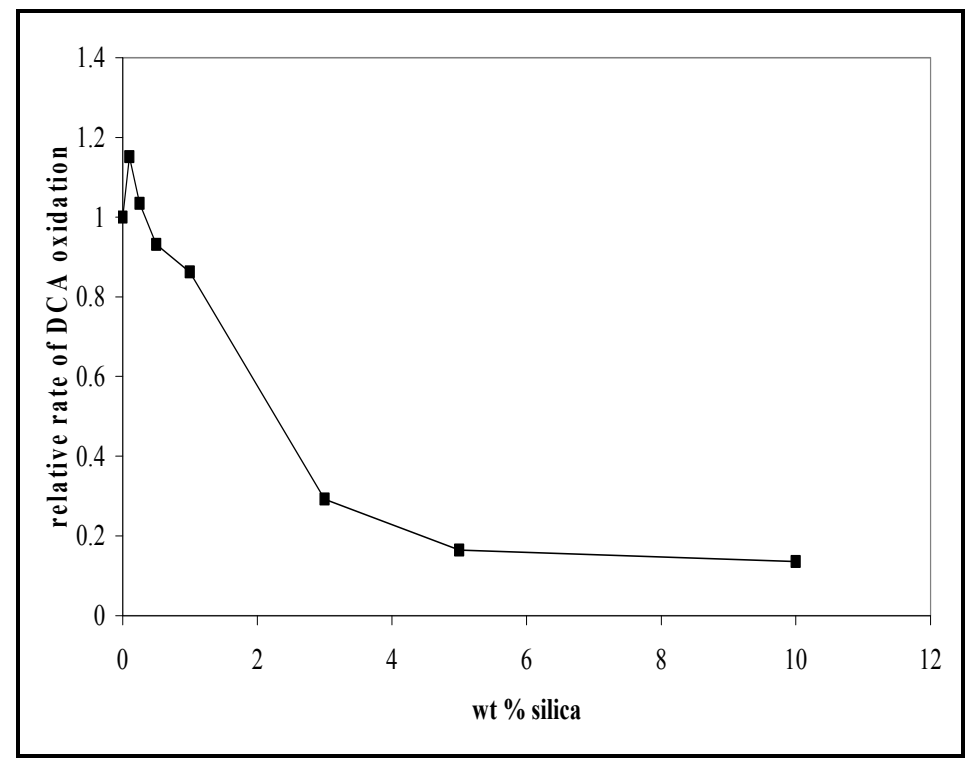

\section{Photocatalytic Reduction of DPPH and Photogreying}

To determine the effect of a hydrous oxide coating layer on photocatalytic reduction two reactions, the reduction of DPPH (1,1-diphenyl-2-picrylhydrazyl radical) and photogreying of $\mathrm{TiO}_{2}$ were used [26,32].

\subsection{Photocatalytic Reduction of DPPH}

The photocatalyzed reduction of dipheny picryl hydrazine $(\mathrm{DPPH}), \mathrm{e}^{-}+\mathrm{DPPH}^{\cdot} \rightarrow \mathrm{DPPH}^{-}$, was used to monitor the effect of surface oxides on the photocatalysis of a reduction reaction. DPPH is a neutral molecule and therefore adsorption on the catalyst is less likely to be affected by changes its surface charge than is an ionic species such as the dichloroacetate anion. Work, by Truscott [32] had demonstrated that the photocatalyzed reduction rate, depended on the type of $\mathrm{TiO}_{2}$, and followed the order P25 (uncoated, mainly anatase) > Tayca MT100T (coated rutile) > Ishihara FPT4-12 (coated rutile) $\geq$ Tayca MT100Z (coated rutile). The rate of decay was not significantly affected when oxygen was replaced by argon. Nor did either either water or propan-2-ol affect the observed kinetics. Since both water and propanol would be expected to adsorb at the $\mathrm{TiO}_{2}$ surface, this suggests that DPPH reduction is not sensitive to changes in adsorption. The experiments were carried on a dispersions of $\mathrm{TiO}_{2}\left(0.25 \mathrm{~g} \mathrm{dm}^{-3}\right)$ in a solution of DPPH $\left(2 \times 10^{-4} \mathrm{M}\right)$ in a 50:50 mix of mineral oil and caprylic acid triglyceride (MOTG; supplied by Uniqema) using a similar cell to that used for the propan-2-ol oxidation. The stable free radical, diphenyl picryl hydrazine, DPPH, is purple and has a broad absorption from 400 to $800 \mathrm{~nm}$ centred at $520 \mathrm{~nm}$ [26]. The DPPH readily captures an electron to form $\mathrm{DPPH}^{-}$which then captures a proton from the solvent to form yellow $\mathrm{DPPH}_{2}$. The $\mathrm{DPPH}_{2}$ has a UV absorption band whose tail extends into the visible but is very small by $520 \mathrm{~nm}$. Consequently the absorption peak of DPPH disappears as it is reduced and, following Truscott et al. [32] the rate of 
photocatalytic reduction of DPPH was monitored by following the decrease of the $520 \mathrm{~nm}$ absorption, as described by Truscott et al. [32] and by Egerton and Mattinson [26]. The results of Figure 9A show an approximately linear decrease in absorbance with increasing exposure time and the results of Figure 9B show the effect of coating level on the rate at which the $520 \mathrm{~nm}$ absorbance decreases.

Figure 9. (A) The change in $520 \mathrm{~nm}$ Absorbance of DPPH over time for a selection of $\mathrm{TiO}_{2} /$ silica catalysts (2S): $0 \mathrm{wt} \%(\mathbf{\square}) ; 0.1 \mathrm{wt} \%$ (घ); $3 \mathrm{wt} \%(\mathbf{\square}) ; 10 \mathrm{wt} \%(\mathbf{\square})$. (B) The rates of $\mathrm{DPPH}$ photoreduction for the $2 \mathrm{~S}$ series of silica/ $/ \mathrm{TiO}_{2}$ catalysts, relative to that of rutile $\# 2$.

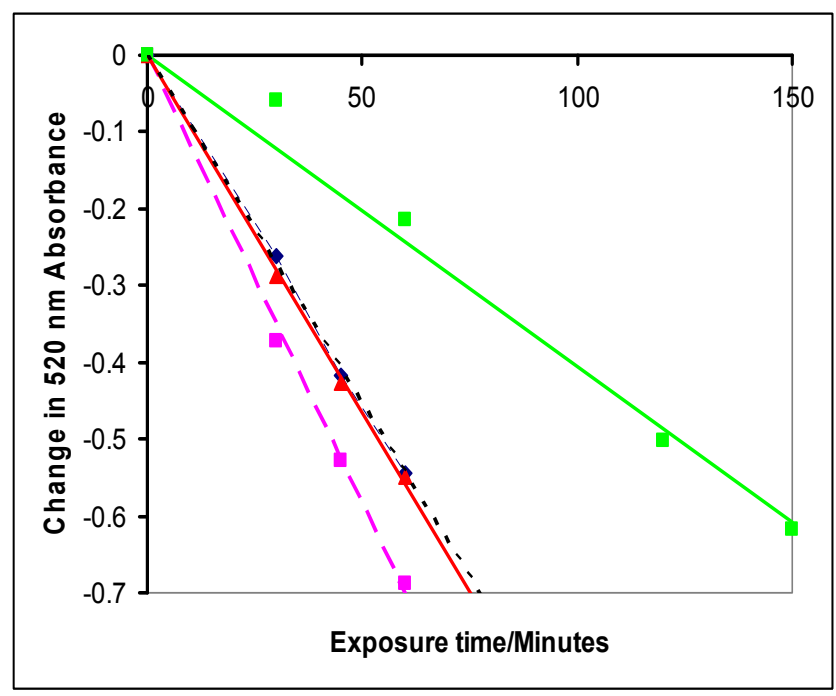

(A)

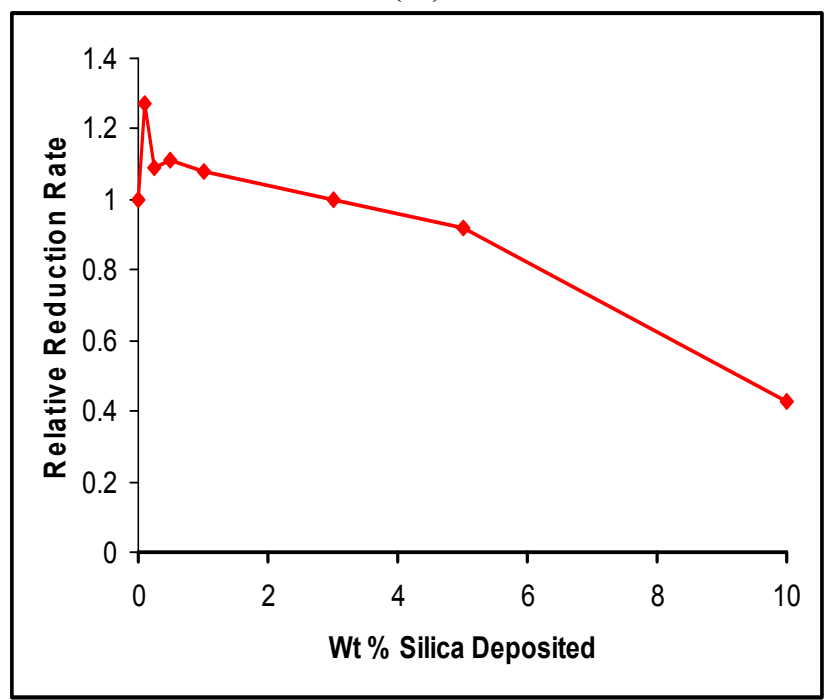

(B)

\subsection{Photogreying}

In the absence of oxygen, and in the presence of a hole acceptor, $\mathrm{TiO}_{2}$ particles turn grey when exposed to UV light [33]. Formation of $\mathrm{Ti}^{3}+$ has been demonstrated when deoxygenated $\mathrm{TiO}_{2}$ suspensions were irradiated and then cooled to low temperatures to allow $\mathrm{Ti}^{3+}$ detection by ESR [34-37]. It is therefore reasonable to assume that the photogreying process is associated with the steps such as: 


$$
\begin{gathered}
\mathrm{TiO}_{2}+\mathrm{h} v \rightarrow \mathrm{e}^{-}+\mathrm{h}^{+} \\
\mathrm{Ti}^{\mathrm{IV}}+\mathrm{e}^{-} \rightarrow \mathrm{Ti}^{3+}
\end{gathered}
$$

Because DPPH photoreduction monitors the ability of UV-generated photoelectrons to migrate to the surface and reduce another molecule, whereas photogreying is related to the reduction of the $\mathrm{Ti}^{\mathrm{IV}}$, photogreying provides an interesting comparison with DPPH reduction.

Dispersions of $\mathrm{TiO}_{2}\left(5 \mathrm{wt} . \%\right.$ ) in a $\mathrm{C}_{12}-\mathrm{C}_{15}$ alkyl benzoate (Finsolv) medium were prepared by milling the mixtures for $15 \mathrm{~min}$ at $5000 \mathrm{rpm}$ with a "MINI MOTOR" mill (Eiger Torrance MK M50 VSE TFV), filled $(70 \%)$ with zirconia beads $(0.8-1.25 \mathrm{~mm})$. These dispersions were then transferred to a specially constructed cell as described by Egerton and coworkers [26,33] and placed on a turnTable $12 \mathrm{~cm}$ beneath a 75W UV light source. An oxygen free environment was maintained by a quartz cover on the cell held in place by a movable catch. Measurements of $L^{*}$, related to the reflectance of the $\mathrm{Y}$ illuminant (maximum intensity at $550 \mathrm{~nm}$ ), as defined by the International Commission on Illumination (CIE), by the equation

$$
L^{*}=116\left(Y / Y_{0}\right)^{1 / 3}-16
$$

were taken every 30 min for 240 min using a Minolta chroma meter (CR-300), previously calibrated against a white tile $\left(L^{*}=97.95\right)[26]$.

Figure 10. (A) Photogreying, monitored as change in $L^{*}$ value (a measurement of the sample's reflectance of the CIE Y illuminant centred on $550 \mathrm{~nm}$ ) as a function of irradiation time for the $2 \mathrm{~S}$ series of silica-coated $\mathrm{TiO}_{2}$ samples: $0 \mathrm{wt} \%(\mathbf{\square}) ; 0.1 \mathrm{wt} \%$

(घ); $5 \mathrm{wt} \%(\mathbf{\square}) ; 10 \mathrm{wt} \%(\mathbf{\square}) \mathrm{SiO}_{2}$. (B) The decrease in photogreying value $\left(\Delta \mathrm{L}_{120}\right)$ with increasing silica content. $\Delta \mathrm{L}_{120}$ is the total change in the $\mathrm{L}$ value after $120 \operatorname{mins}\left(\mathrm{L}_{0}{ }_{0}-\mathrm{L}^{*}{ }_{120}\right)$. (C) Decrease in photogreying $(\mathbf{a},-)$ and $\operatorname{DPPH}^{\bullet}$ reduction $(\boldsymbol{\Delta},---)$ for $\mathrm{SiO}_{2} \geq 1 \%$. (Figure 10A and $\mathrm{C}$ are reprinted from Ref. [26] with permission from Elsevier).

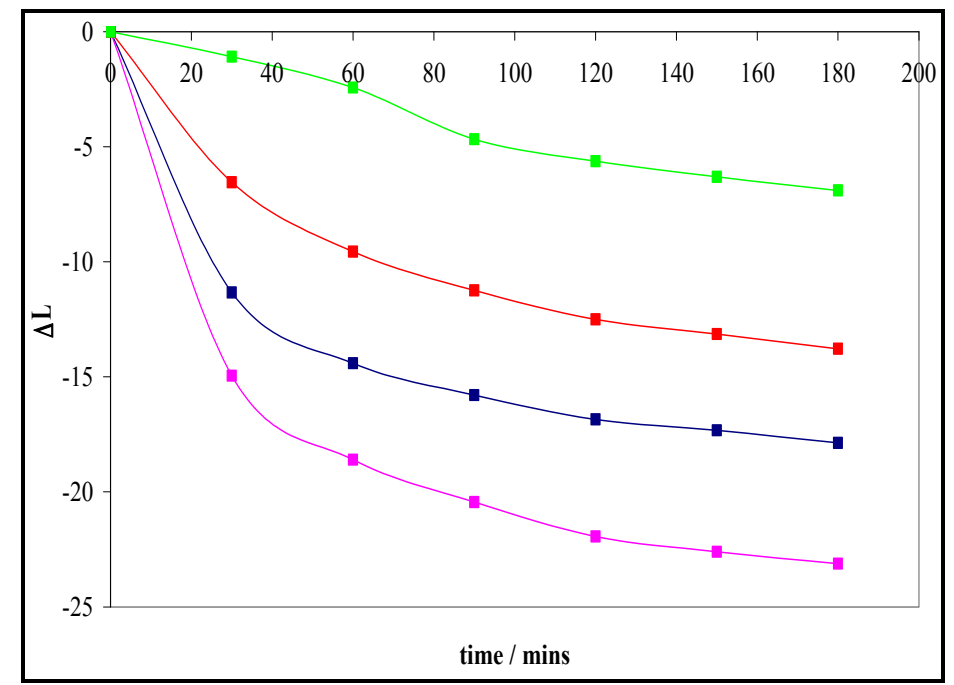

(A) 
Figure 10. Cont.

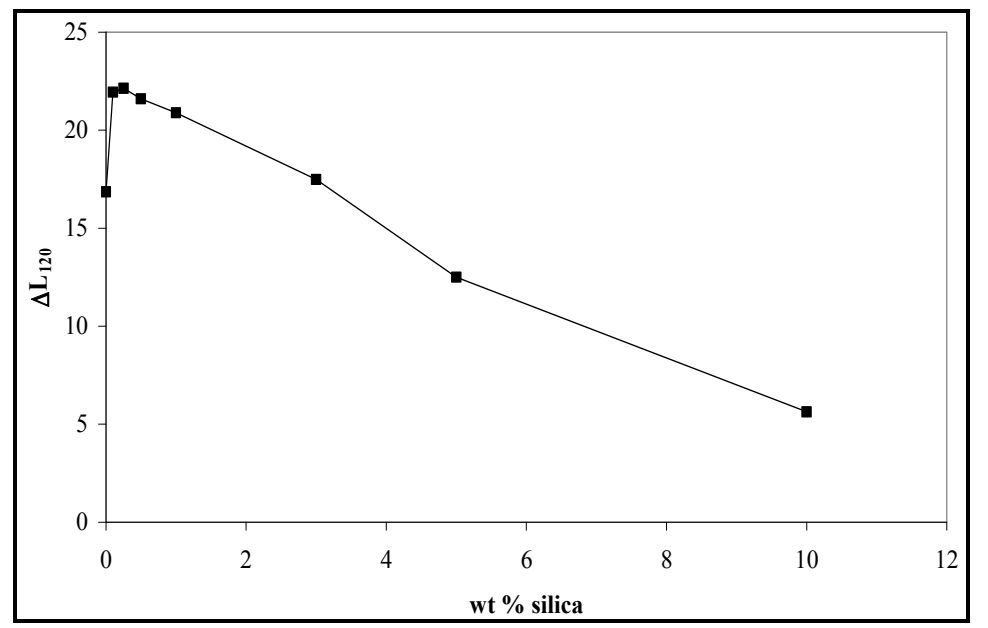

(B)

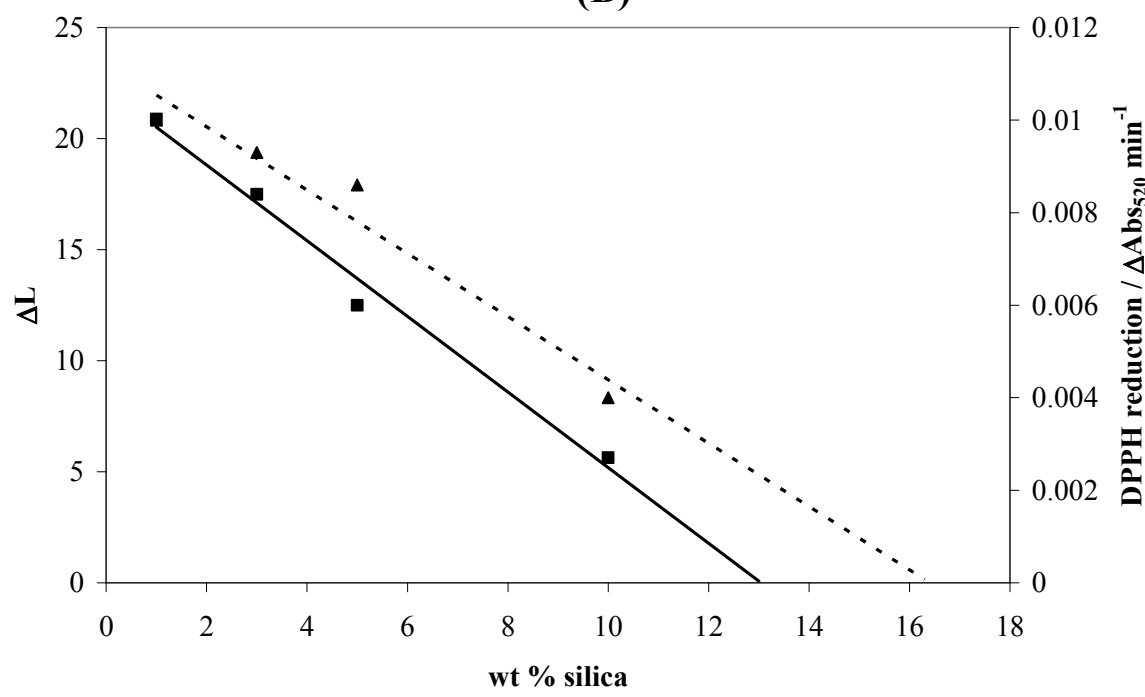

(C)

The effect of silica on the photogreying of $\mathrm{TiO}_{2}$ (rutile) nanoparticles is shown in Figure 10A-C [28]. In all cases photogreying of all samples exhibits a similar pattern; a sharp initial drop in L followed by a slower drop at longer time intervals. Interestingly, like all previous reactions, there is in fact an increase in photogreying at low silica loadings. This suggests that the cause of the initial increase is not associated with adsorption. At silica loadings $\geq 1 \%$ there is a reasonable parallel between the rates of DPPH reduction and the rate of photogreying. An exact correspondence between the two would tend suggest that the Ti(IV) that are reduced during the photogreying process are, at the rutile surface. However the results do not exclude the possibility that electrons are first trapped at bulk $\mathrm{Ti}^{4+}$ centres and then migrate to the surface [37], since the presence of at least two different trapped electron sites either on or in high area rutiles of this type has been confirmed by low temperature ESR studies [38].

\section{The Influence of Phosphate on Photocatalytic Disinfection}

The foregoing discussion has focused on the effects of surface alumina and of surface silica on the photocatalytic activity of rutile. In this final sub-section of relevant results, work on the effect of phosphate on the disinfection activity of P25 ( $~ 80 \%$ anatase) is summarized. Phosphate ions adsorb on 
the surface of $\mathrm{TiO}_{2}$ photocatalysts and even small amounts can poison the activity [39-42]. Phosphate ions such as $\mathrm{H}_{2} \mathrm{PO}_{4}{ }^{-}$adsorb strongly on titanium dioxide surfaces probably by an exchange reaction with surface hydroxyl groups [39]. The adsorption is so strong that it inhibits the anatase-rutile transformation that can otherwise be induced by milling Degussa P25 [40] and Okazaki et al. reported that phosphate inhibits the adsorption of basic amino-acids [41]. Matthews and coworkers demonstrated that adsorption at concentrations as low as $1 \mathrm{mM}$, phosphate adsorption reduces photo-oxidation of simple organics (ethanol, aniline and salicylic acid) by $\sim 50 \%$ [42]. As an example of this effect, the results in Figure 11 show how the disinfection activity of P25 for. E. coli. decreased as the phosphate concentration in solution increased [43]. For a concentration of $3.7 \mathrm{mM} \mathrm{KH}_{2} \mathrm{PO}_{4}$ the rate constant for the disinfection of E. Coli. of initial concentration $2.7 \times 10^{6} \mathrm{cfu}$ fell from $3.1 \times 10^{-2}$ to $1.0 \times 10^{-2} \mathrm{~min}^{-1}$ ).

Figure 11. The effect of increasing concentrations of phosphate on the disinfection of E. coli. by P25 (Initial concentration $2.7 \times 10^{6}$ c.f.u.). measured as the $\%$ of bacteria no longer viable after $20 \mathrm{~min}$ irradiation.

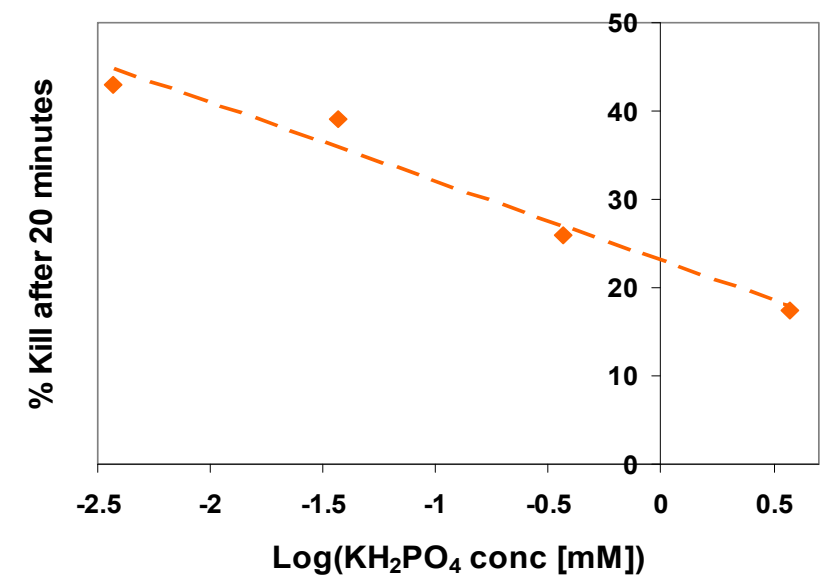

\section{An Overview of the Effect of Surface Inorganics on Photoactivity}

\subsection{The Effectiveness of the Different Coating Procedures}

Silica may be deposited as a surface layer on pigmentary, $250 \mathrm{~nm}$ rutile [17], and this surface layer has been demonstrated by transmission electron microscopy [18,27], vapour adsorption [27] secondary ion mass spectrometry and XPS [27,44] The same method has been used to deposit silica on two different batches of nanoparticulate, $\sim 130 \mathrm{~m}^{2} \mathrm{~g}^{-1}$, rutile and, although the coating is not observable in electron micrographs of the treated nano-rutile, both the i.r. studies of adsorbed $\mathrm{N}_{2}$ and the solid-state n.m.r. results for series $2 \mathrm{~S}$ samples confirm that silica deposition has occurred. i.e., the silica is on not $i n$, or beside the rutile. There is also evidence that alumina deposits on $250 \mathrm{~nm}$ titania $[14,16,18]$ and two coating procedures, a relatively complex one for series $1 \mathrm{~A}$, and a simpler procedure series $2 \mathrm{~A}$, have been used to do this on the high area rutile. The results in this review indicate that the presence of these inorganic species on the $\mathrm{TiO}_{2}$ surface modify photocatalysis of both oxidation and reduction. The greater the deposition of inorganic, the greater the decrease in activity. For similar amounts deposited, the reduction in photocatalytic activity follows the sequence: 


$$
\mathrm{SiO}_{2}>\mathrm{Al}_{2} \mathrm{O}_{3} \text { (complex) }>\mathrm{Al}_{2} \mathrm{O}_{3} \text { ( simple) }
$$

Studies by others have shown that phosphate adsorbs on $\mathrm{TiO}_{2}$ and reduces photocatalytic activity. This conclusion has been confirmed by the effect of dissolved phosphate on the ability of P25 to kill E. coli.

It has been demonstrated that transition metal ions, dopants, either on or in the rutile, can provide localized levels within the band gap. These can act as traps or electron-hole recombination centres and hence influence recombination rates [45] and therefore photocatalytic activity [46-48]. However, it seems improbable that such simple species as alumina, silica and phosphate act in this way. Instead, it has been shown that the alumina and silica forming a coating which blocks access to the rutile of both nitrogen [15] and organic probe molecules [27]. Because both silica and alumina are insulators, the coating prevents the transfer of photogenerated electrons or holes from the rutile particles to the interface with the fluid in which the rutile is dispersed and therefore lower the photocatalytic activity.

If, for the purpose of an order of magnitude estimate, the rutile particles are taken to be spheres of radius $r$ given by $r=3 / S \rho_{\mathrm{R}}$, (where $S$ is the surface area and $\rho_{\mathrm{R}}, 4.2 \mathrm{~g} \mathrm{~cm}^{-3}$, is the density of rutile) 140 $\mathrm{m}^{2} \mathrm{~g}^{-1}$ rutile corresponds to $r=5.1 \mathrm{~nm}$. If these spherical particles are and to be covered by a uniform layer of alumina of thickness $\mathrm{t}$ and density $\rho_{\text {coat }}$ of $\sim 2.1 \mathrm{~g} \mathrm{~cm}^{-3}$ (since the hydrous coating is less dense than crystalline alumina) the amount of alumina required to cover the surface is given by

$$
\begin{aligned}
& \text { Weight } \% \text { of } \mathrm{Al}_{2} \mathrm{O}_{3}=\frac{\text { Weight }}{\text { Weight }} \frac{\mathrm{Al}_{2} \mathrm{O}_{3}}{\left(\mathrm{TiO}_{2}+\mathrm{Al}_{2}\right.} \frac{}{\left.\mathrm{O}_{3}\right)} \times 100 \\
& =\frac{4 \pi r^{2} t \rho_{\text {coat }}}{4 / 3\left(\pi r^{3}\right) \rho_{t}+4 \pi r^{2} t \rho_{\text {coat }}} \times 100 \\
& =\frac{3 t \rho_{\text {coat }}}{r \rho_{t}+3 t \rho_{\text {coat }}} \times 100
\end{aligned}
$$

If it is further assumed that an effective coating requires a uniformly thick hydrous oxide coating of $1 \mathrm{~nm}$ thickness, the estimated weight of the surface coating corresponds to a loading of $\sim 24 \%$. (taking advantage of the fact that $\rho_{R}=2 \rho_{\text {coat }}$ ). The figure is of the same order as the 20 to $30 \%$ estimated from the intensity dependence of i.r.-active nitrogen on alumina (Figure 6A) and silica (Figure 6B).

The idea that the coating then blocks the transfer of both photogenerated holes and electrons is supported by the reduction of photocatalytic oxidation and photocatalytic reduction and also by the coating coverages necessary to eliminate photocatalytic oxidation of propan-2-ol (Figure 6A,B) being broadly similar to those necessary for eliminating formation of i.r. active nitrogen. Detailed differences may occur because the coatings are more porous to nitrogen than to propan-2-ol or because the nitrogen adsorption was measured on rutile outgassed at $350{ }^{\circ} \mathrm{C}$. The different effectiveness for reducing propan-2-ol oxidation of alumina coatings from series 1A (Figure 6A) and 2A (Figure 7B) is attributed either to a more effective coating brought about by the more careful coating sequence of series $1 \mathrm{~A}$ or to an effect of the phosphate dispersant which was used only for series $1 \mathrm{~A}$. It is postulated that there are differences in the uniformity of the coating or in the coating porosity.

In general the activity patterns which led to the conclusions of the preceding paragraph are broadly paralleled by the other results, particularly those for DPPH photo-reduction which like propan-2-ol 
photo-oxidation requires $\geq 10 \%$ silica to reduce the activity to below $1 / 3$ of that of uncoated rutile (Figure 9B).

\subsection{Dependence of Photocatalysis on Coating Induced Changes in Adsorption}

The very significant decrease in activity for DCA degradation at silica levels as low as $3 \mathrm{wt} . \%$ contrasts with the $>10 \%$ necessary for propan-2-ol and DPPH. This difference is probably influenced by decreased adsorption of the DCA anion which is the dominant species at the reaction $\mathrm{pH}$ of 3 . Because $\mathrm{TiO}_{2}$ prepared by hydrolysis of $\mathrm{TiCl}_{4}$ has a point of zero charge (p.z.c.) of $\geq 5.5[8,28,49]$, the surface of uncoated $\mathrm{TiO}_{2}$ surface is positively charged at $\mathrm{pH} 3$. However, as shown in Figure 12, based on results of Tooley for rutile \#2 [28] and on Furlong, Sing and Parfitt for $\mathrm{TiCl}_{4}$-derived rutile (but allowing for the much lower area of their rutile) [50], deposited silica lowers the isoelectric point. As shown in Figure 12, the p.z.c. of the catalyst falls significantly at silica levels between 4 and 5\%. Both sets of results imply that the surface charge at $\mathrm{pH} 3$ is very small and that, therefore, adsorption of the DCA anion on silica-coated rutile would be greatly reduced. Since adsorption is a necessary prerequisite for the direct hole degradation of DCA, the reduced adsorption is the probable reason for the photocatalytic activity reaching its minimum value at between 3 and 5\% silica, a much lower figure than the $\sim 10 \%$ silica necessary to reduce propan-2-ol oxidation. (Figure $6 \mathrm{~B}$ ). Thus, the DCA results suggest that the reduced catalytic activity due to suppressed charge-transfer on silica coated surfaces is supplemented by the consequences of reduced adsorption of the pollutant. The conclusion is consistent with the that reached by Enriquez and Pichat [31] that that the hole attack mechanism for carboxylic acids is much more sensitive to surface area, and therefore adsorption, variation than is the (diffusible) $\mathrm{OH}$ radical mechanism.

Figure 12. The dependence of measured p.z.c.'s on the weight of silica precipitated onto rutile \#2 $\left(130 \mathrm{~m}^{2} \mathrm{~g}^{-1}\right)$. and p.z.c.'s measured by Furlong et al. [50], but "correcting” the silica levels to allow for the lower surface area of the rutile used by them $\left(20 \mathrm{~m}^{2} \mathrm{~g}^{-1}\right) \mathbf{m}$.

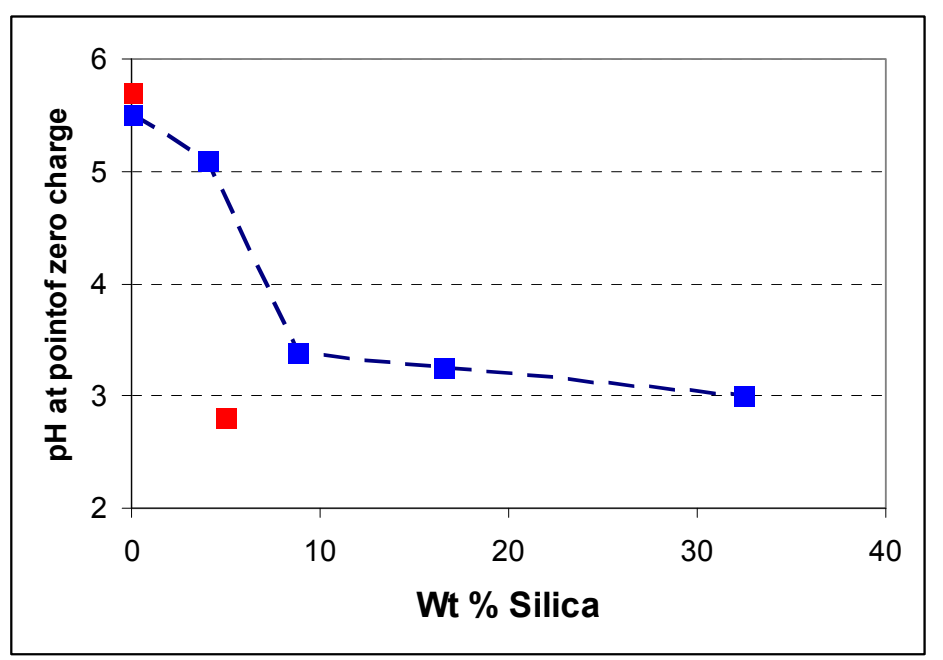


Since, at 8.9, the p.z.c. of $\gamma$-alumina is higher, not lower, than that of $\mathrm{TiO}_{2}$ [8] the effects of alumina deposition on titanium dioxide will be to increase the p.z.c. and therefore anionic reactants are more, not less, likely to adsorb on alumina coated rutile. In coatings containing both silica and alumina a general increase in p.z.c. with increasing fraction of alumina has been reported [51] but the coating sequence is also important [52].

\subsection{Possible Perturbation of the Photocatalytic Results Caused by Dispersion Changes}

A small increase in activity for oxidation of propan-2-ol (Figure 7B) and dichloroacetate (Figure 8) and reduction of DPPH. (Figure 9B) was observed at very low silica coating levels. Whilst it is possible that this increase occurs because of changes in particles charge of the rutile caused by the deposition of silica, it is more probably associated with changes in the degree of particle dispersion. Changes in titania dispersion induced by milling have been demonstrated to influence photocatalytic rates $[53,54]$. Normally, improved dispersion reduces photocatalytic activity because the reduction in effective size of the dispersed particles leads to increased absorption near $350 \mathrm{~nm}$ [55]. The UV light is therefore absorbed in a shorter path length and consequently by a smaller number of particles. Thus, in any given particle more charge carriers are formed. Since the probability of recombination is increased as the number of charge carriers increases, the proportion of UV-generated electrons and holes that reaches the particle surface and initiates a catalytic reaction is reduced [56]. It is this recombination which often leads to an $I^{0.5}$ dependency of photocatalytic rate on intensity I. For a fixed flux of incident photons the catalytic activity decreases, i.e., the photonic efficiency decreases. (Appreciation of this somewhat counter-intuitive conclusion may be helped by an over-simplified comparison of the activity of 10 separate crystals each of which absorb one photon — giving a rate proportional to $10 \times \sqrt{ } 1$ — with that of 1 crystal which absorbs 10 photons-giving a rate proportional to $1 \times \sqrt{ } 10$.) As shown in Figure 13, this effect for propan-2-ol has been confirmed by measuring the oxidation rate before and after milling the rutile suspension. The photocatalytic activity of the unmilled, more poorly dispersed system was $50 \%$ greater than that of the milled suspension. It is therefore not unreasonable to attribute the observed ca. $20 \%$ initial increase in activity to poorer dispersibility of the silica coated rutiles induced by increased aggregation of the coated samples.

Figure 13. Decreased rate of photocatalytic oxidation of propan-2-ol to acetone caused by 30 min milling of the high area rutile \#2. 0 min. mill (-, $\mathbf{\Delta})$; 30 min. mill (---, $\mathbf{\square})$ [28].

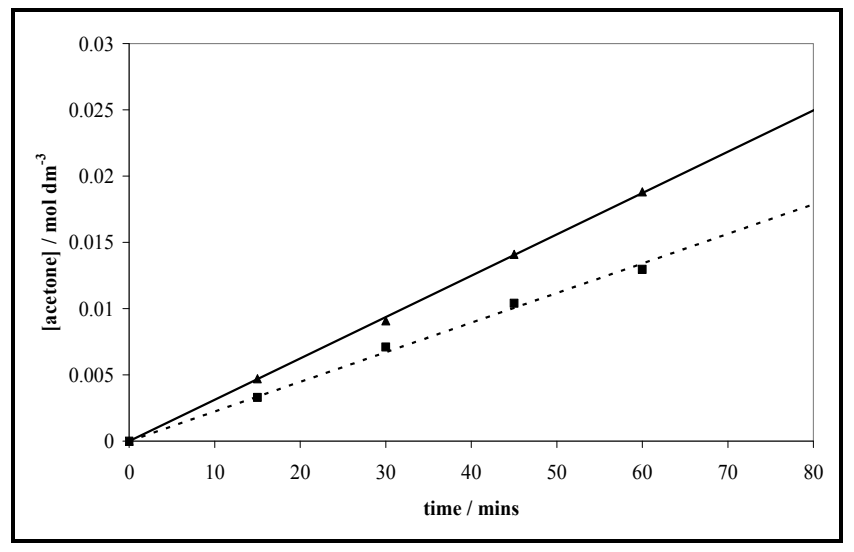




\section{The Implications of These Results for Practical Treatment of Water}

Practical photocatalytic degradation of organic pollutants must take into account the influence of other chemicals and one intention of this review was to consider how inorganic species adventitiously present in aqueous systems may modify the photocatalytic activity of $\mathrm{TiO}_{2}$ suspensions. As a simplified illustration of a mechanism by which this may occur under laboratory conditions, the specific case of surface alumina is now considered. Evidence of adsorption of aluminium ions on titania, prepared like the rutile used in this study by hydrolysis of $\mathrm{TiCl}_{4}$, was systematically generated in a series of studies by Healy and co-workers and facilitates this consideration [8-11]. $\mathrm{TiO}_{2}$ particles in aqueous suspension carry a $\mathrm{pH}$ dependent surface charge. At a particular $\mathrm{pH}$ - the p.z.c - the $\mathrm{TiO}_{2}$ surface is uncharged; below the p.z.c - the $\mathrm{TiO}_{2}$ surface is positive; above the p.z.c the surface is negative. At the p.z.c., the rate of flocculation or coagulation, $\mathrm{D}$, is limited only by diffusion but if the liquid $\mathrm{pH}$ differs from the $\mathrm{TiO}_{2}$ p.z.c. by more than 0.5 units the similarly charged particles repel one another and flocculation rates are reduced to some value $\mathrm{R}$. Healy used the ratio $\mathrm{D} / \mathrm{R}$ - the stability ratio-as a measure of the suspension's colloidal stability and showed that in the presence of $\mathrm{KNO}_{3}$, an indifferent electrolyte, the stability ratio of a $\mathrm{TiO}_{2}$ suspension reached its minimum at $\mathrm{pH} \sim 6$, i.e., at the same $\mathrm{pH}$ as the p.z.c., of $\mathrm{TiO}_{2}$ determined by electrophoresis [8]. For $\gamma$-alumina, the p.z.c. shifted to $\sim 8.9$ but the same pattern of results was obtained and in both cases the minimum of $\mathrm{D} / \mathrm{R}$ was independent of the $\mathrm{KNO}_{3}$ concentration [8]. If however, the stability of a titania sol was measured in increasing concentrations (from $4 \times 10^{-7}$ to $2.1 \times 10^{-5} \mathrm{M}$ ) aluminium nitrate solutions the p.z.c. shifted from $\mathrm{pH} 5.9$ (zero $\mathrm{Al}(\mathrm{III})_{\mathrm{aq}}$ ) to $\mathrm{pH} 9$ in $2.1 \times 10^{-5} \mathrm{Al}\left(\mathrm{NO}_{3}\right)_{3}$, as shown in Figure 14. This was interpreted as consistent with progressive nucleation of a coating of aluminium hydroxide with the complete coating, corresponding to formation of a hydrated alumina surface on the $\mathrm{TiO}_{2}$, occurring at Al(III) concentrations $\geq 12 \mu \mathrm{M}$ [9]. As indicated in the introduction, significantly higher concentrations of aluminium can occur in many effluent streams. Further, since much of the aluminium in freshwater may be present as fine particles it is important to note that when mixed suspensions of titania and alumina in $\mathrm{KNO}_{3}$ were left for $24 \mathrm{~h}$ their coagulation behaviour became practically identical to that of a single $\mathrm{Al}_{2} \mathrm{O}_{3}$ dispersion. It was concluded that $\mathrm{Al}^{3+}$ had dissolved from the alumina particles and reprecipitated on the titania surface to give particles that were superficially identical with alumina [10,11]. As indicated in Section 2.1, additional routes to surface deposition of both alumina and silica occur in natural waters.

The implication of the results of Healy's group is that $\mathrm{TiO}_{2}$ catalysts in Al-containing aqueous streams will acquire an alumina coating and the results reviewed in this paper imply that this coating will directly affect (reduce) the photoactivity of the catalysts. The results from silica coating and dissolved phosphate that have been summarized in this review suggest that other inorganics may behave similarly. In addition to directly affecting charge-carrier transfer-as described above for propan-2-ol, the changes in surface potential caused by layers of alumina and silica will influence the adsorption of charged species - as described in Section 6.2 for the dichloroacetate ion on silica-coated $\mathrm{TiO}_{2}$. Changes in the p.z.c. to higher pH's will accompany the formation of surface alumina layers, changes to lower $\mathrm{pH}$ values will accompany the formation of silica layers. Many dye molecules are ionic $[3,4]$. For example, azo dyes are made in both anionic and cationic forms and their adsorption and subsequent decolourations is known to depend on the surface charge of the catalyst. Thus, in 
addition to the direct effects on photocatalysis exemplified in this review, inorganic oxide coatings will also have an indirect effect-via modified adsorption —on many dye decolouration reactions. Both effects should be considered when designing practical photocatalytic treatment systems. There is little use in designing catalysts with activities greater than that of a standard titania if the practical advantage of the greater activity is negated by increased adsorption of dissolved inorganic species.

Figure 14. Variation of the p.z.c. of $\mathrm{TiO}_{2}$ with increasing concentration of $\mathrm{Al}\left(\mathrm{NO}_{3}\right)_{3}$. The plot is derived from results of Wiese and Healy [8]. The same group reports a p.z.c of 8.9 for $\gamma$-alumina.

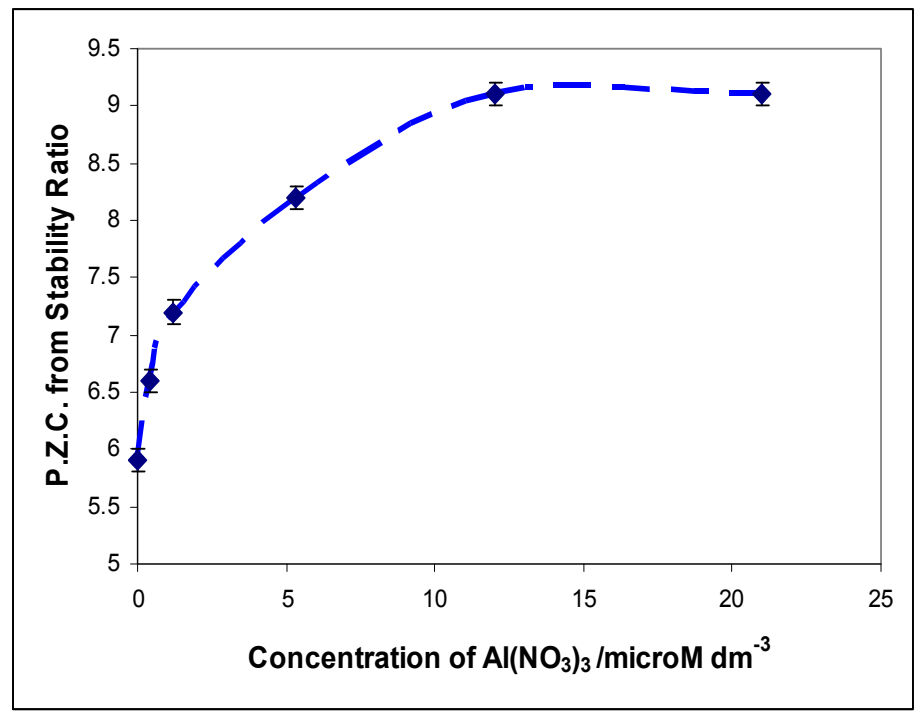

\section{Summary and Conclusions}

Both the infrared spectroscopic studies of adsorbed nitrogen and the solid state n.m.r. measurements that have been reviewed in this paper confirm that silica and alumina can be deposited to form a coating on the surface of rutile. Classical colloid studies had previously demonstrated that both suspended alumina particles and dissolved aluminium ions change the surface properties (e.g., the point of zero charge) of suspended $\mathrm{TiO}_{2}$ particles, and had suggested that an alumina layer forms on the surface of $\mathrm{TiO}_{2}$. Together, these results imply that $\mathrm{TiO}_{2}$ in Al-containing aqueous streams will acquire an alumina coating. It has been demonstrated that such coatings reduce the photocatalytic activity of $\mathrm{TiO}_{2}$ for both photo-oxidation and photo-reduction reactions.

Since both silica and alumina are insulators it is suggested that any coating blocks the interaction of photogenerated charge-carriers with reactant molecules. This suggestion is consistent with order of magnitude estimates of the amount silica or alumina that is needed to cover the surface. Earlier measurements of vapour adsorption had indicated that the hydrophilic nature of rutile, alumina-coated rutile and silica-coated rutile are similar. Therefore, for an uncharged hydrophilic molecule, such as propanol, the main mechanism by which silica or alumina coating reduces photoactivity is by suppression of charge transfer to the surface.

Silica coatings lower the point of zero charge (p.z.c.) of coated $\mathrm{TiO}_{2}$; alumina coatings raise the p.z.c. This change in the p.z.c. affects the adsorption of charged species. It is demonstrated that silica coatings lessen photoactivity for the $\mathrm{pH} 3$ degradation of DCA at lower coating levels than are 
necessary to lower the activity for propan-2-ol oxidation. It is suggested that in this case reduction of photocatalytic activity is caused by lessened adsorption of DCA in addition to the suppression of charge transfer. This effect of modified adsorption is likely to be important for photocatalytic decolouration of ionic dyes.

It is also demonstrated that silica coatings have similar effects on both photogreying of the $\mathrm{TiO}_{2}$ and photoreduction of the DPPH radical.

\section{Acknowledgments}

A sequence of able and creative research students generated the results in this review. I particularly thank Ian Tooley (I.r. of adsorbed $\mathrm{N}_{2}$ and propan-2-ol photocatalysis) John Mattinson (propan-2-ol, dichloroacetic acid, DPPH and photogreying studies) Samia Kosa (photocatalytic disinfection) and Liwei Wang (Photogreying). I thank them all for their careful experimental work and stimulating discussions. I also thank Paul Christensen (Newcastle U.) for access to his i.r. spectroscopic facilities and David Apperley (Durham U.) and the EPSRC solid-state NMR service for measuring the NMR spectra. I thank the UK EPSRC and ICI Uniqema (now Croda) for supporting both IT and JM, the EPSRC/DTI for support of Liwei Wang via the ACORN programme, and the Cultural Bureau of the Royal Kingdom of Saudi Arabia for support for SK.

\section{Conflict of Interest}

The author declares no conflict of interest.

\section{References}

1. Arslan-Aloton, I. Advanced Oxidation of Textile Industry Dyes. In Advanced Oxidation Processes for Water and Wastewater Treatment; Parsons, S., Ed.; IWA Publishing: London, UK, 2004; pp. 302-328.

2. Karkmaz, M.; Puzenat, E.; Guillard, C.; Herrmann, J.M. Photocatalytic degradation of the alimentary azo dye amaranth. Mineralization of the azo group to nitrogen. Appl. Catal. B 2004, 51, 183-194.

3. Muruganandham, M.; Swaminathan, M. Solar driven decolourisation of reactive yellow 14 by advanced oxidation processes in heterogeneous and homogeneous media. Dyes Pigments 2007, 72, 137-143.

4. Upadhyay, S.; Liss, P.S.; Jickells, T.D. Sorption Model for Dissolved Aluminium in Freshwaters. Aquat. Geochem. 2002, 8, 255-275.

5. Mackin, J.E.; Aller, R.C. Processes affecting the behavior of dissolved aluminium in estuarine waters. Mar. Chem. 1984, 14, 213-232.

6. Hydes, D.J.; Liss, P.S. Behavior of Dissolved Aluminum in Estuarine and Coastal Waters. Estuar. Coast. Mar. Sci. 1977, 5, 755-776.

7. Tipping, E. Modelling A1 competition for heavy metal binding by dissolved organic matter in soil and surface waters of acid and neutral pH. Geoderma 2005, 127, 293-304. 
8. Wiese, G.R.; Healy, T.W. Coagulation and electrokinetic behavior of $\mathrm{TiO}_{2}$ and $\mathrm{Al}_{2} \mathrm{O}_{3}$ colloidal dispersions. J. Colloid Interf. Sci. 1975, 51, 427-433.

9. Wiese, G.R.; Healy, T.W. Adsorption of $\mathrm{Al}(\mathrm{III})$ at the $\mathrm{TiO}_{2}-\mathrm{H}_{2} \mathrm{O}$ interface. J. Colloid Interf. Sci. 1975, 51, 434-442.

10. Healy, T.W.; Wiese, G.R.; Yates, D.E.; Kavanagh, B.V. Heterocoagulation in mixed oxide colloidal dispersions. J. Colloid Interf. Sci. 1973, 42, 647-649.

11. Wiese, G.R.; Healy, T.W. Heterocoagulation in mixed $\mathrm{TiO}_{2}-\mathrm{Al}_{2} \mathrm{O}_{3}$ dispersions. J. Colloid Interf. Sci. 1975, 52, 458-467.

12. Harrison, J.A.; Frings, P.J.; Beusen, A.H.W.; Conley, D.J.; McCrackin, M.L. Global importance, patterns, and controls of dissolved silica retention in lakes and reservoirs. Global Biogeochem. Cycle 2012, 26, doi:10.1029/2011GB004228.

13. Mackin, J.E.; Aller, R.C. The effects of clay mineral reactions on dissolved Al distributions in sediments and waters of the Amazon continental-shelf. Cont. Shelf Res. 1986, 6, 245-262.

14. Egerton, T.A.; Everall, N.J.; Tooley, I.R. Characterization of $\mathrm{TiO}_{2}$ Nanoparticles Surface Modified with Aluminum Stearate. Langmuir 2005, 21, 3172-3178.

15. Egerton, T.A.; Tooley, I.R. The surface characterisation of coated titanium dioxide by FTIR spectroscopy of adsorbed nitrogen. J. Mater. Chem. 2002, 12, doi:10.1039/b105903n.

16. Howard, P.B.; Parfitt, G.D. Precipitation of silica-alumina on titanium-dioxide surfaces. Croat. Chem. Acta 1977, 50, 15-30.

17. Iler, R.K. Product comprising a skin of dense, hydrated amorphous silica bound upon a core of another solid material and process of making same. US Patent No. 2,885,366, 5 May 1959.

18. Egerton, T.A. The modification of fine powders by Inorganic Coatings. Kona 1998, 16, 46-59.

19. Gesenhues, U. Coprecipitation of hydrous alumina and silica with $\mathrm{TiO}_{2}$ pigment as substrate. $J$. Coll. Inter. Sci.1994, 168, 428-436.

20. Exley, C.; Birchall, J.D. Hydroxy aluminosilicate formation in solutions of low total aluminium concentration. Polyhedron 1992, 11, 1901-1907.

21. Birchall, J.D.; Chappell, J.S. Aluminum, water chemistry, and Alzheimers-Disease. Lancet 1989, 1, 953-953.

22. Marsac, R.; Davranche, M.; Gruau, G.; Dia, A.; Bouhnik-Le Coz, M. Aluminium competitive effect on rare earth elements binding to humic acid. Geochim. Cosmochim. Acta 2012, 89, 1-9.

23. Cabaniss, S.E. Forward Modeling of Metal Complexation by NOM: II. Prediction of Binding Site Properties. Environ. Sci. Technol. 2011, 45, 3202-3209.

24. Sen Kavurmaci, S.; Bekbolet, M. The Role of Oxidative Treatment on the Trivalent Cation Complexation Properties of Natural Organic Matter. J. Adv. Oxid. Technol. 2010, 13, 212-220.

25. Engelhardt, G.; Michel, D. High Resolution Solid State NMR of Silicates and Zeolites; Wiley: New York, NY, USA, 1987.

26. Egerton, T.A.; Mattinson, J.A. Comparison of photooxidation and photoreduction reactions on $\mathrm{TiO}_{2}$ nanoparticles. J. Photochem. Photobiol. A 2007, 186, 115-120.

27. Day, R.E.; Egerton, T.A. Surface Studies of TiO, Pigment with Especial Reference to the Role of Coatings. Colloid Surface 1987, 23, 137-155.

28. Mattinson, J.A. Effect of Inorganic Surface Treatment on $\mathrm{TiO}_{2}$ Photoactivity. Ph.D. Thesis, Newcastle University, Newcastle-upon-Tyne, UK, November 2008. 
29. Kraeutler, B.; Bard, A.J. Heterogeneous photocatalytic decomposition of saturated carboxylic-acids on tio2 powder-decarboxylative route to alkanes. J. Am. Chem. Soc.1978, 100, 5985-5992.

30. Bahnemann, D.W.; Kholuiskaya, S.N.; Dillert, R.; Kulak, A.I.; Kokorin, A.I. Photodestruction of dichloroacetic acid catalyzed by nano-sized TiO2 particles. Appl. Catal. B 2002, 36, 161-169.

31. Enriquez, R.; Pichat, P. Different net effect of $\mathrm{TiO}_{2}$ sintering temperature on the photocatalytic removal rates of 4-chlorophenol, 4-chlorobenzoic acid and dichloroacetic acid in water. $J$. Environ. Sci. Health A 2006, 41, 955-966.

32. McGarvey, D.J.; Lyth, P.L.; Guest, P.J.; Dransfield, G.; Truscott, T.G. Photoactivity tests of TiO2-based inorganic sunscreens - Part 1: Non-aqueous dispersions. J. Photochem. Photobiol. B. 2000, 59, 151-174.

33. Egerton, T.A.; Kessell, L.M.; Tooley, I.R.; Wang, L.W. Photogreying of $\mathrm{TiO}_{2}$ nanoparticles. $J$. Nanopart. Res. 2007, 9, 251-260.

34. Howe, R.F.; Gratzel, M. EPR observation of trapped electrons in colloidal $\mathrm{TiO}_{2}$. J. Phys. Chem. 1985, 89, 4495-4499.

35. Nakaoka, Y.; Nosaka, Y.Y. ESR investigation into the effects heat treatment and crystal structure of radical produced over irradiated $\mathrm{TiO}_{2}$ powder. J. Photochem. Photobiol. A 1997, 110, $299-305$.

36. Attwood, A.L.; Murphy, D.M.; Edwards, J.L. An EPR study of thermally and photochemically generated oxygen radicals on hydrated and dehydrated titania surfaces. Res. Chem. Intermediat. 2003, 29, 449-465.

37. Deskins, N.A.; Dupuis, M. Electron transfer via polaron hopping in bulk $\mathrm{TiO}_{2}$ : A density functional theory characterization. Phys. Rev. B 2007, 75, 195212-195217.

38. MacDonald, I.R.; Howe, R.F.; Zhang, X.; Zhou, W. In situ EPR studies of electron trapping in a nanocrystalline rutile. J. Photochem. Photobiol. A 2010, 216, 238-243.

39. Flaig-Baumann, R.; Hermann, M.; Boehm, H.P. Chemistry of titanium dioxide surface .3. Reactions of basic hydroxyl on surface. Z. Anorg. Allg. Chem. 1970, 372, 296-297.

40. Criado, J.; Real, C. Mechanism of the inhibiting effect of phosphate on the anatase-rutile transformation induced by thermal and mechanical treatment of $\mathrm{TiO}_{2}$. J. Chem. Soc. Faraday Trans. 1983, 79, 2765-2771.

41. Okazaki, S.; Aoki, T.; Tani, K. The adsorption of basic alpha-amino-acids in an aqueous-solution by titanium (iv) oxide. Bull. Chem. Soc. Jpn. 1981, 54, 1595-1599.

42. Abdullah, M.; Low, G.K.C.; Matthews, R.W. Effects of common inorganic anions on rates of photocatalytic oxidation of organic-carbon over illuminated titanium-dioxide. J. Phys. Chem. 1990, 94, 6820-6825.

43. Christensen, P.A.; Curtis, T.P.; Egerton, T.A.; Kosa, S.A.M.; Tinlin, J.R. Photoelectrocatalytic and photocatalytic disinfection of E. coli suspensions by titanium dioxide. Appl. Catal. B 2003, 41, 371-386.

44. Egerton, T.A.; Parfitt, G.D.; Kang, Y.; Wightman, J.P. XPS analysis of uncoated and silica-coated titanium-dioxide powders. Colloid Surface 1983, 7, 311-323.

45. Mizushima, K.; Tanaka, M.; Asai, A.; Iida, S.; Goodenough, J.B. Impurity levels of iron-group ions in $\mathrm{TiO}_{2}$. J. Phys. Chem. Solids 1979, 40, 1129-1140.

46. Martin, S.T.; Morrison, C.L.; Hoffmann, M.R. Photochemical Mechanism of Size-Quantized Vanadium-Doped $\mathrm{TiO}_{2}$ Particles. J. Phys. Chem. 1994, 98, 13695-13704. 
47. Palmisano, L.; Augugliaro, V.; Sclafani, A.; Schiavello, M. Activity of chromium-ion-doped titania for the dinitrogen photoreduction to ammonia and for the phenol photodegradation. $J$. Phys. Chem. 1988, 92, 6710-6713.

48. Egerton, T.A.; Kosa, S.A.M.; Christensen, P.A. Photoelectrocatalytic disinfection of E. coli suspensions by iron doped $\mathrm{TiO}_{2}$. Phys. Chem. Chem. Phys. 2006, 8, 398-406.

49. Furlong, D.N.; Parfit, G.D. Electrokinetics of titanium dioxide. J. Colloid. Interf. Sci. 1978, 65, 548-554.

50. Furlong, D.N.; Sing, K.S.W.; Parfitt, G.D.P. Precipitation of silica on titanium dioxide surfaces. 1. Prepartion of coated surfaces and examination by electrophoresis. J. Colloid Interf. Sci. 1979, 69, 409-419.

51. Parfitt, G.D.; Ramsbotham, J. Study of surface properties of coated titanium dioxide pigments by electrophoresis. J. Oil Colour Chem. Ass. 1971, 54, 356-358.

52. Losoi, T. Surface studies of titanium dioxide pigments. J. Coating Technol. 1989, 61, 57-63.

53. Egerton, T.A.; Harrison, R.W.; Hill, S.E.; Mattinson, J.A.; Purnama, H. Effects of particle dispersion on the measurement of semi-conductor photocatalytic activity. J. Photochem. Photobiol. A 2010, 216, 268-274.

54. Egerton, T.A.; Tooley, I.R. Effect of changes in $\mathrm{TiO}_{2}$ dispersion on its measured photocatalytic activity. J. Phys. Chem. B 2004, 108, 5066-5072.

55. Egerton, T.A.; Tooley, I.R. UV absorption and scattering properties of inorganic-based sunscreens. Int. J. Cosmetic Sci. 2012, 34, 117-122.

56. Egerton, T.A.; King, C.J. The influence of light intensity on photoactivity in $\mathrm{TiO}_{2}$ pigmented systems. J. Oil. Colour Chem. Assoc. 1979, 62, 386-391.

(C) 2013 by the authors; licensee MDPI, Basel, Switzerland. This article is an open access article distributed under the terms and conditions of the Creative Commons Attribution license (http://creativecommons.org/licenses/by/3.0/). 